\title{
Reef Vision: a citizen science program for monitoring the fish faunas of artificial reefs
}

James H. Florisson ${ }^{* 1,2,3}$, James R. Tweedley ${ }^{2,3}$, Tim H. E. Walker,3, Jennifer A. Chaplin ${ }^{2,3}$

${ }^{1}$ Recfishwest, $3 / 45$ Northside Dr, Hillarys Western Australia 6025, Australia

${ }^{2}$ Centre for Sustainable Aquatic Ecosystems, Harry Butler Institute Murdoch University, 90 South St, Murdoch, Western Australia, 6150, Australia

${ }^{3}$ School of Veterinary and Life Sciences, Murdoch University, 90 South St, Murdoch, Western Australia, 6150, Australia

* Corresponding author

Phone number: + 61892463366

Email: james@recfishwest.org.au 


\begin{abstract}
There has been a marked increase in the number of artificial reefs being deployed around the world, many of which are designed to increase catches of recreationally-targeted fish species. As artificial reef deployments should be accompanied by clear and measurable goals and subsequent environmental impact monitoring and performance evaluation, there is a need to develop cost-effective monitoring programs. This study provides proof of concept for a citizen science approach to monitoring the fish faunas of artificial reefs (Reef Vision). Recreational fishers were recruited to collect video samples using baited remote underwater video systems and submit the resultant footage for analysis and interpretation by professional scientists. Reef Vision volunteers were able to collect enough data of sufficient quality to monitor the Bunbury and Dunsborough artificial reefs in Geographe Bay, south-western Australia. Data were extracted from the footage and used in robust univariate and multivariate analyses, which determined that a soak time of 45 minutes was sufficient to capture $95 \%$ of the number of species, abundance, diversity and community composition of the fish fauna. The potential for these data to detect differences in the characteristics of the fish fauna between reefs and seasons was also investigated and confirmed. With the continuing deployment of artificial reefs around the world, the use of similar cost-effective citizen science monitoring approaches can help determine the effectiveness these structures in achieving their aims and goals and provide valuable data for researchers, managers and decision makers. Projects such as Reef Vision can also benefit volunteers and communities by enhancing social values, creating ownership over research projects and fostering stewardship of aquatic resources.
\end{abstract}

Keywords: baited remote underwater video; community engagement; habitat enhancement; recreational fishing 


\section{Introduction}

Artificial reefs are widely deployed around the world and are increasingly becoming a part of the seascape in coastal environments, including in Australia (Diplock, 2010; Fabi et al., 2015). The term 'artificial reef' is variously used (Seaman and Jensen, 2000), however, most usage falls within the broad definition of Sutton and Bushnell (2007), i.e. "one or more objects of natural or human origin deployed purposefully on the seafloor to influence

physical, biological or socioeconomic processes related to living marine resources". One of the most common applications is as a tool in fisheries management to improve fishing (Seaman, 2007; Fabi et al., 2015; Becker et al., 2017) and, in regions such as Australia and the United States of America, particularly recreational fishing (Seaman and Jensen, 2000; Lowry et al., 2014). These installations are popular with recreational fishers as they can enhance fishing experiences and catch rates by providing access to target species and, in the longer term, stimulate in situ production, thereby increasing total fish stocks (Bohnsack, 1989; Brickhill et al., 2005; Cresson et al., 2014; Smith et al., 2016).

The artificial reefs used in fisheries enhancement in developed countries are now typically purpose-built, rather than constructed from materials-of-opportunity (Diplock, 2010; Lowry et al., 2014), ideally with considerable planning directed towards ensuring that the reef design, configuration and location is suited to its designated purpose (Diplock, 2010; Fabi et al., 2015). Post deployment of the structures, it is crucial to assess the extent to which a reef is achieving the intended purpose (Seaman and Jensen, 2000; dos Santos and Zalmon, 2015; Becker et al., 2017), and to determine the type and magnitude of any environmental impacts (Department of Fisheries, 2012; Department of the Environment, 2016; International Maritime Organization, 2016). Without such an assessment, there is a risk of repeatedly reusing suboptimal or even undesirable reef materials and designs, and incurring large costs in the process (Diplock, 2010). For example, the size, configuration and location of a reef is known to influence the density, biomass, and composition of the fish fauna and the long-term productivity of a reef, as well as fishing effort (Bohnsack et al., 1991; Jordan et al., 2005; Fabi et al., 2015). However, how these interactions manifest is still poorly understood (Diplock, 2010; Lowry et al., 2014). Information on the spatial and temporal variability of the 
fish fauna on an artificial reef can be used to put in place actions that maximise returns from the fish resources on the reef (dos Santos and Zalmon, 2015), to understand ecosystem-level responses of fishes to the reef (Scott et al., 2015) and to integrate the reef into a broader management framework (Lowry et al., 2014; Fabi et al., 2015). Thus, long-term monitoring of the fish assemblages associated with artificial reefs for fisheries enhancement is essential (dos Santos and Zalmon, 2015; Becker et al., 2017). This requirement can, however, add considerable costs to an artificial reef project (Fabi et al., 2015).

The financial costs of monitoring the fish faunas of an artificial reef could potentially be reduced by involving citizen scientists. Citizen science describes an approach where members of the public, usually non-experts or non-professionals, participate in scientific research or monitoring on a voluntary basis (Chase and Levine, 2016; McKinley et al., 2017). This approach has been applied in a variety of settings (Dickinson et al., 2012; Cigliano et al., 2015; Follett and Strezov, 2015; McKinley et al., 2017) and is being increasingly used in natural resource monitoring (Boakes et al., 2016; Chase and Levine, 2016). Although the use of citizen science in marine research and monitoring has recently started to gain traction (e.g. Fairclough et al., 2014; Thiel et al., 2014; Anderson et al., 2017), Cigliano et al. (2015) have pointed out that there is considerable potential to expand in this area. Citizen science monitoring can be a cost-effective method of data collection, whilst also increasing stakeholder engagement and buy-in (Dickinson et al., 2010; Fairclough et al., 2014; AcevesBueno et al., 2015; McKinley et al., 2017). However, if the program is poorly designed and managed, it can result in unsystematic data collection, leading to uncertainty about the efficacy of the data (Dickinson et al., 2010; Boakes et al., 2016). It is also important to consider the 'hidden costs' of administering citizen science programs, such as the recruiting, training and retaining volunteers (Thiel et al., 2014; McKinley et al., 2017). Ultimately, the costs and benefits of using citizen science in natural resource monitoring are context dependent (see Chase and Levine, 2016; McKinley et al., 2017). Success or failure will depend on the outcome of the interactions between a range of key variables, such as the type and goals of the monitoring, the tasks and levels of responsibility given to the member of the public and how the project is administered (Chase and Levine, 2016). 
The overall objective of this study was to provide a proof of concept of a citizen scientist program (called Reef Vision), where recreational fishers used Baited Remote Underwater Video systems (BRUVs) to monitor the fish fauna of two artificial reefs. These purpose-built reefs were recently deployed in a marine embayment (Geographe Bay) on south-western coast of Australia, with the aim of enhancing recreational fishing opportunities and experiences. A BRUV monitoring method was chosen because it is cost-effective (Cappo et al., 2003); relatively robust to user skills and bias (Thompson and Mapstone, 1997); unaffected by depth and time limitations unlike, for example, diver surveys (Willis et al., 2000); actively attracts fish to the camera, thereby increasing the chances of observing more fish (Stobart et al., 2015); and has been successfully used by scientists to study the fish fauna of artificial reefs (e.g. Folpp et al., 2013; Scott et al., 2015; Becker et al., 2017). BRUVs also provide a permanent record of the data, which means that fish identifications and counts can be done later and checked for accuracy by qualified scientists, thus removing a potential source of error from the data set (Cappo et al., 2003; Whitmarsh et al., 2017). The specific aims of the study were to (i) elucidate whether sufficient quantities of video footage could be collected to constitute an effective monitoring regime; (ii) determine quantitatively the duration of a video that needs to be examined before there is no significant change in the characteristics of the fish fauna; and (iii) investigate whether data of sufficient quality can be extracted from the video footage to enable robust univariate and multivariate analysis of any spatial and/or temporal changes in fish faunal composition.

\section{Materials and methods}

Study site

The citizen scientists monitored two artificial reefs in Geographe Bay, a shallow, open embayment in south-western Australia (Fig. 1). This region experiences a Mediterranean climate, with hot dry summers and cool wet winters (Gentilli, 1971; Belda et al., 2014). Geographe Bay is well flushed with ocean water and the salinity is around full strength seawater throughout the year (Fahrner and Pattiaratchi, 1995). Water temperatures range 
from a minimum of $\sim 13{ }^{\circ} \mathrm{C}$ in winter to maximum of $\sim 26^{\circ} \mathrm{C}$ in summer (Australian Institute of Marine Science, 2017). Tides are semi-diurnal with a low range (usually $<1 \mathrm{~m}$, i.e. microtidal; Tweedley et al., 2016b) and water movement is predominantly wind-driven (Fahrner and Pattiaratchi, 1995; Dunn et al., 2014). The substrate consists of unconsolidated sediments over clay and limestone formations, which are exposed in some areas, and seagrass coverage (predominantly Posidonia sinuosa), is extensive throughout much of the bay (McMahon et al., 1997; Van Niel et al., 2009). Recreational fishing is a popular activity in Geographe Bay (Geographe Catchment Council, 2008).

Each of the two artificial reefs comprises 30 'Fish Box' modules (Fig. 2b), placed in six clusters of five units, and deployed over a four-hectare area (Fig. 1). Each module, which measured $3 \mathrm{~m}^{3}$ and weighed 10 tonnes, was constructed from steel-reinforced concrete with curved cross braces designed to promote upwelling. Both reefs were deployed in April 2013, creating the South West Artificial Reef Trial Project (Tweedley et al., 2016a). The reefs were placed in Geographe Bay in the vicinity of two urban centres, i.e. Bunbury and Dunsborough (Fig. 1), and within $5 \mathrm{~km}$ of boat ramps to allow for easy boat-based access by recreational fishers. The Bunbury reef lies at a depth of $\sim 17 \mathrm{~m}$, whereas the Dunsborough reef is at $\sim 27 \mathrm{~m}$ (Fig. 1). These reefs were designed to increase the abundance of recreationally-important fish species, such as the sparid Chrysophorus auratus, and the carangids Pseudocaranx spp. and Seriola hippos, and thus improve recreational fishing opportunities.

\section{Citizen science program}

Citizen scientists were recruited and managed through a branded citizen science program called 'Reef Vision' (Recfishwest, 2017) operated by Recfishwest, the peak body representing recreational fishers in Western Australia. Recreational fishers who lived in close proximity to one of the reefs and fished regularly were recruited through a targeted print, radio and social media campaign. Applicants were interviewed to ensure their suitability for the project, i.e. they owned a suitable boat and safety equipment, held a valid skipper's licence and fished regularly; with the six most suitable participants recruited to monitor each 
reef (note this number was selected solely based on the cost of the equipment provided to each participant). Each participant attended a short ( 2 hour) training workshop held locally in October 2015, where the aims and importance of the research, as well as instructions on how to use the camera equipment, were presented. At the workshop, each volunteer was provided with a BRUV (Fig. 2a), waterproof log book, data storage devices, prepaid envelopes, bait vouchers, training manuals and the contact numbers of project staff able to help with any issues.

To facilitate retention, all participants were invited to join a closed Facebook page, which provided a platform for volunteers to interact with each other and project staff. The amount and timing of any monitoring done by a participant was at the discretion of the participant, although it was recommended that each person should monitor one of the artificial reefs for at least one 60 minute period each per month, if possible, over the course of a year (October 2015 to September 2016). While this flexibility had the potential to impact on the number of videos collected, it was preferred to a more regimented approach, which has been shown to result in low recruitment and retention rates in other citizen science projects (Dickinson et al., 2010).

The BRUVS (Fig. 2a) employed in Reef Vision were designed by Ecotone Consulting and constructed from readily available materials to increase cost effectiveness and ease of use by volunteers (Florisson, 2015; Tweedley et al., 2016a). Each BRUV frame was constructed from Polyvinyl Chloride (PVC) irrigation pipe (rated to $891 \mathrm{kPa}$ ) and $\mathrm{PVC}$ cement, and covers an area of $\sim 580 \mathrm{~mm} \times 450 \mathrm{~mm}$ (Fig. 2). The frame was connected to two stabilising skids, each filled with four $680 \mathrm{~g}$ lead weights to ensure the unit was negatively buoyant (5.5 $\mathrm{kg}$ total weight) and did not fall over upon landing on the substratum. A GoPro Hero 4 Silver Action Camera, which has an ultra-wide angle lens and the ability to record video footage with resolution of $1080 \mathrm{p}$ at 60 frames per second, was mounted on the pipe using brackets. The camera was equipped with a waterproof housing rated to $40 \mathrm{~m}$. A bait arm, with a length of $600 \mathrm{~mm}$ from the BRUV central point, and a plastic mesh bait bag (180 $\mathrm{mm} \times 100 \mathrm{~mm})$ placed $500 \mathrm{~mm}$ from the camera, was suspended $150 \mathrm{~mm}$ above the seafloor. These dimensions are consistent with those used in other BRUV studies (e.g. Ellis and DeMartini, 
1995; Willis and Babcock, 2000; Heagney et al., 2007). To aid BRUV deployment and retrieval, a $35 \mathrm{~m}$ rope and float was attached to a tie point (stainless steel loop) in the central PVC cross brace. Each of the twelve BRUVs cost a total of AU\$685 to produce. The largest individual cost was the labour required to construct the BRUV (\$315), followed by the GoPro camera and SD card (\$254), with the material needed to build the frame and attachments (ropes, floats, boom and bait bag) only costing $\$ 116$ (17\% of the total unit cost).

\section{Sampling methodology}

Following training, participants began to deploy BRUVs on the two artificial reefs in October 2015. On each sampling trip to their assigned reef (either Bunbury or Dunsborough), a volunteer was asked to deploy the BRUV on one of the five clusters (chosen randomly) for at least 60 minutes and fill out a log book. The book contained the date and time the BRUV was deployed and retrieved, the latitude and longitude of the deployment, cluster number and any other observations (e.g. how many people were fishing and what fish they caught). Prior to deployment, $500 \mathrm{~g}$ of Australian Sardine Sardinops sagax was placed in the bait bag of the BRUV, as the soft oily flesh of this species is known to attract fish. This fish is regarded as the most effective bait for BRUVs in Western Australia (Watson et al., 2010; Goetze et al., 2011; Dorman et al., 2012; Mallet and Pelletier, 2014). Once back onshore, participants downloaded the video footage on to a USB drive and posted it, together with the corresponding log-book sheet, to project staff at Murdoch University using the pre-paid envelope. Volunteers were encouraged to watch their videos and could share footage (Fig. 2b) on social media, particularly the closed project Facebook page.

\section{Data extraction}

Prior to analysis, each video was examined to determine the quality of the footage. Videos in which the camera faced into the sediment or towards the surface of the water were excluded, as were videos that did not capture the reef modules and those in which the water and/or light clarity precluded the accurate identification of fish. One video was selected, at 
random, from each reef, in each month between October 2015 and September 2016 for analysis (i.e. 12 videos per reef, total of 24). The MaxN, i.e. the maximum number of individuals of a particular species seen in any one video frame (Fig. 2b; Whitmarsh et al., 2017), was recorded for each five-minute interval of each video from the moment the BRUV touched the substrate until 60 minutes later. Taxa were identified to the lowest possible taxonomic level, typically species.

\section{Statistical analysis}

Soak time analyses

A suite of univariate and multivariate statistical analyses were employed to determine the length of video that needed to be observed before the characteristics of the fish fauna exhibited no significant change with increasing time. The MaxN of each species in each fiveminute interval of each of the 12 videos collected from each of the two reefs were subjected to the DIVERSE routine in PRIMER v7 (Clarke and Gorley, 2015) to calculate the number of species, total MaxN (i.e. the sum of the MaxN values for individual species) and Simpson's Diversity Index. The resultant 288 values (i.e. 24 videos [12 per reef] x 12 five minute intervals) for each of the three univariate variables were then averaged to provide a single value for each variable in each five-minute interval at each reef and thus remove any potentially confounding influence of month. Increases in the mean for each of the three univariate variables with increasing five minute time intervals were plotted as rarefaction curves (Ugland et al., 2003).

Changes in species composition over time on each reef were also examined. In this case, the MaxN values of each species in each five-minute interval at each reef were firstly dispersion weighted, by dividing the counts for each species by their mean index of dispersion, i.e. the average of the variance to mean ratio in replicate videos (Clarke et al., 2006). This pre-treatment then ensures all species have equivalent variability by downweighting the abundances of heavily-schooling species, such as the carangid Trachurus novaezelandiae, whose numbers are erratic over replicate videos relative to those species 
which return more consistent values, e.g. the aracanid Anoplocapros amygdaloides (Veale et al., 2014; Potter et al., 2016). These dispersion-weighted data were then square-root transformed to balance the contribution of relatively abundant species, compared to those with lower MaxN values (Clarke et al., 2014a). The transformed data for each five-minute interval were then averaged across the 12 replicates for each reef and used to construct a Bray-Curtis resemblance matrix. This matrix was subjected to hierarchical agglomerative clustering (CLUSTER; Clarke et al., 2014a) to determine the time intervals that were $\geq 95 \%$ similar in terms of their species composition. The matrix was also used to construct a nonmetric Multi-Dimensional Scaling (nMDS) ordination plot (Clarke, 1993), which provides a visual representation of the changes in fish faunal composition over time for both reefs.

The dispersion-weighted and square-root transformed MaxN data for each time interval on each reef were used to construct a shade-plot (Clarke et al., 2014b). The shade plot is a visualization of the averaged data matrix, where a white space for a species demonstrates that the fish was not recorded, while the depth and colour of shading, ranging from grey shades through the spectrum to black, represents increasing values for the abundance of that species in that time interval. The averaged samples ( $x$ axis of the plot) are ordered from lowest to highest time interval for each reef. Species ( $y$ axis of the plot) are ordered to optimise the seriation statistic $\rho$ by non-parametrically correlating their resemblances to the distance structure of a linear sequence and constrained by a cluster dendrogram (Clarke et al., 2014a).

\section{Differences in fish fauna between artificial reefs and seasons}

On the basis of the above analysis, a video interval of 45 minutes was deemed appropriate to provide a robust determination of the fish fauna present on each of the artificial reefs (see Results). Thus, the MaxN of each species after 45 minutes from each reef in each of the 12 months were extracted from the above dispersion-weighted and square-root transformed data. These data were used by DIVERSE to calculate the number of species, total MaxN and Simpson's Diversity Index. Prior to subjecting the data for each variable to 
Permutational Multivariate Analysis of Variance (PERMANOVA; Anderson et al., 2008) in Primer v7, each variable was tested to ascertain if a transformation was required to meet the test assumptions of homogeneity of variance and normality. This was achieved by plotting the $\log _{e}$ mean against the $\log _{e}$ standard deviation of every group of samples and determining the slope of the relationship, comparing it to the criteria in Clarke et al. (2014a). This analysis indicated that only total MaxN required transformation and was $\log _{e}(\mathrm{X}+1)$ transformed. The data for each of the three dependent variables were used to construct a Euclidean distance matrix, which were, in turn, subjected to a two-way PERMANOVA to determine if the values for that variable differed significantly between Reef (2 levels; Bunbury and Dunsborough) and Season (2 levels; Summer [October-March] and Winter [AprilSeptember]). In these, and all subsequent tests, the null hypothesis of no significant difference among a priori groups was rejected if the significance level $(P)$ was $\leq 0.05$.

The dispersion-weighted and square-root transformed species composition data were used to construct a Bray-Curtis resemblance matrix, which was subjected to the same twoway PERMANOVA design used above. In this analysis PERMAOVA was primarily used to test for the presence of an interaction and a subsequent two-way Analysis of Similarities (ANOSIM; Clarke and Green, 1988) test used to determine the relative size of the overall Reef and Season effects on fish faunal composition using the universally scaled $R$ statistic (Lek et al., 2011). An nMDS ordination plot was constructed form the above resemblance matrix to show the extent to which fish faunal composition differed between the reefs. To simplify and further illustrate the differences between Reef and Season, a centroid nMDS plot was produced using a distances among centroids matrix, which creates averages in the 'BrayCurtis space' from the six replicate samples representing each season in each reef (Lek et al., 2011). A shade plot was constructed from the transformed and averaged data matrix to illustrate the trends exhibited by species with respect to Reef and Season. Note that as 44 species were recorded, many of which only occurred in a few samples, the shade plot was restricted to those 18 and 17 species that represented $>2.5 \%$ of the total fish abundance in a reef and season, respectively. 


\section{Results}

Citizen science data collection

Twelve main volunteers were utilised in the project, with six monitoring each of the two artificial reefs, and a further 20 participants involved as crew members. Over the course of the year-long study (October 2015 to September 2016) there was an attrition rate of 16\%, with two of the 12 volunteers leaving the project due to unrelated issues (i.e. receiving employment in other parts of Western Australia and ill health). These two volunteers were replaced with two new and trained personal to ensure the quality and quantity of footage collected was maintained.

Throughout the sampling period 59 and 52 individual videos were collected from the Bunbury and Dunsborough artificial reefs, respectively, totalling $\sim 10,000$ minutes of footage (Table 1). At least four videos were recorded from each reef in each month with the exception of June and August in Bunbury and June and September in Dunsborough. In no months were data not collected from each reef. Typically greater numbers of videos were collected in between November to March, i.e. around the austral summer, with fewer video collected in the austral winter (June and August; Table 1).

\section{Fish faunal composition}

A total of 44 species, representing 29 families were recorded from the 24 videos from the two artificial reefs (Table 2). Five species, each of which contributed $\geq 10 \%$ to the total MaxN, comprised the majority of the assemblage (77\% of all individuals). These comprised the pempherid Parapriacanthus elongatus, which lives in close association to the reef modules, the epibenthic kyphosid Neatypus obliquus and labrid Coris auricularis, and the pelagic carangids Trachurus novaezelandiae and Pseudocaranx spp. (Table 2). This latter taxon, which was a target group for the reefs, ranked third in terms of MaxN and was recorded in $75 \%$ of all videos. Other recreationally-targeted species recorded included Seriola hippos, Chrysophrys auratus (both also target species) and Glaucosoma hebraicum and 
Choerodon rubescens. In addition to Pseudocaranx spp., other species that were frequently recorded included C. auricularis, S. hippos and A. amygdaloides (Table 2).

\section{Soak time analyses}

Rarefaction curves for each of the mean number of species, total MaxN and Simpson's diversity index for both the Bunbury and Dunsborough reefs reached an asymptote prior to the 60 minute mark (Fig. 3). Approximately 95\% of maximum values for each univariate variable recorded from the videos from each reef was achieved after $\leq 45$ minutes, with the exception of total MaxN at Bunbury (92\% and $95 \%$ at 45 and 50 minutes, respectively). Moreover, the timing at which the asymptote occurred was similar among the two reefs, despite the values for the number of species and total MaxN always being greater at Dunsborough, whereas the reverse was typically true for Simpson's diversity index (Fig. 3).

A clear pattern of increasing similarity in fish faunal composition among samples for each reef was detected as the duration of the video increased. Thus, for both reefs, samples at 5 and 10 minutes were the most distinct ( $\sim 75 \%$ similarity), whereas those samples derived from video footage at between 40 and 60 minutes were all $>95 \%$ similar (Fig. 4a). As with the univariate variables, similar trends among times were detected for both reefs, despite the fish fauna of the two reefs having a relatively low similarity $(58 \%)$. In other words, larger differences in fish fauna composition were detected between reefs, than among time intervals within a reef, with the same temporal pattern occurring on both reefs. This is shown on the associated nMDS plot, where the samples representing the different time intervals are well separated for each reef, but show the same pattern of increasing proximity to one another with increasing time (Fig. 4b).

The shade plot illustrates that only the mullids Upeneichthys vlamingii (Bunbury) and Parupeneus chrysopleuron (Dunsborough) were recorded for this first time after 45 minutes, albeit their MaxN values were very low (Fig. 5). For most species, including abundant ones such as C. auricularis, Pseudocaranx spp. and N. obliquus, their MaxN values changed little with increasing time. Moreover, even for those species whose abundance on both reefs did 
change with increasing time, e.g. A. amygdaloides and the gerried Parequula melbournensis, these values changed little after 45 minutes (Fig. 5).

The above results suggest that $95 \%$ of the maximum values for the number of species, Simpson's diversity index, fish faunal composition and, to a lesser extent, total MaxN occur within 45 minutes of video footage. Thus, in the case of the Bunbury and Dunsborough artificial reefs, faunal data extracted from 45 minutes of BRUV footage is sufficient to determine accurately the univariate and multivariate characteristics of the fish fauna.

\section{Differences in fish fauna between artificial reefs and seasons}

Two-way PERMANOVA demonstrated that the number of species and total MaxN differed significantly between reefs and seasons, but not the Reef ${ }^{\times}$Season interaction (Table 3a,b). The number of species was greater on the Dunsborough than Bunbury artificial reef and during summer rather than winter (both $\sim 13$ vs 9; Figure 6a,b). Total MaxN values were more than four times larger at Dunsborough (118) than Bunbury (26) and almost three times greater in samples collected in summer (104) as opposed to winter (40). A significant difference between the values for Simpson's diversity index was detected only between reefs (Table 3c), with values in winter being higher than those summer $(0.80$ and 0.65 , respectively; Fig. 6e).

Fish faunal composition was shown by PERMANOVA to differ between reefs and seasons and that there was no interaction between these main effects (Table 3d). The $\bar{R}$ statistic value for Season (0.303) was larger than that for Reef (0.255), indicating that temporal rather than spatial effects were slightly more influential in structuring the fish assemblages of the artificial reefs. This is shown on the nMDS plots where the points representing summer and winter typically form more discrete groups than those for the two artificial reefs (Fig. 7). Species such as C. auricularis, Pesudocaranax spp., C. rubescens and G. hebraicum were more abundant in summer than winter, whereas the reserve was true for A. amygdaloides, S. hippos and the labrid Austrolabrus maculatus (Fig. 8a). Although both artificial reefs contained substantial numbers of $C$. auricularis and A. amygdaloides, fish such 
as N. obliquus, Pseudocaranx spp. and the pinguipedid Parapercis haackei were more abundant at Dunsborough. In contrast, only the relatively uncommon aracanid Anoplocapros lenticularis was comparatively more abundant on the Bunbury artificial reef (Fig. 8b).

\section{Discussion}

There has been a marked increase in the number of artificial reefs being deployed to increase catches of key recreationally-targeted fish species and thus also act as a tool for fisheries and broader ecosystem management (Baine, 2001; Seaman, 2007; Diplock, 2010). Any responsible artificial reef deployment should have clear and measurable performance goals, the successes of which are evaluated using a monitoring program (Becker et al., 2017). However, given the fact that longer term monitoring programs, i.e. those lasting several years, are required to gain a sound understanding of the influence of these artificial structures (e.g. Coll et al., 1998; Relini et al., 2002; dos Santos and Zalmon, 2015), there is a need to develop cost-effective monitoring regimes. This study determined that citizen scientists using BRUVs could collect sufficient quantities of adequate quality data to develop a robust monitoring program for two artificial reefs in a marine embayment in south-western Australia. It follows that this methodology could be used to help to monitor and determine the effectiveness of other artificial reefs in achieving their aims and goals.

\section{Participant involvement}

Each of the 12 main volunteers were asked to each collect a single video of at least 60 minutes duration from their respective reef in each month of the study using the supplied BRUV equipment. If completed successfully, this would provide six replicates from each reef in each month and thus allow for robust statistical examination of the resultant data. Throughout the sampling period, volunteers were able to effectively collect data from both artificial reefs, amassing a total of 111 videos (averaging 4.9 and 4.3 per month from the Bunbury and Dunsborough reefs, respectively). This success is consistent with other studies employing citizen science, which suggest that this method can result in the collection of large 
quantities of data over broad spatial and temporal scales, which could otherwise be cost prohibitive (Silvertown, 2009; Dickinson et al., 2010; Pecl et al., 2014). Moreover, despite, due to financial limitations, only having six volunteers per reef, at least four videos were collected from a reef in 19 of the 24 reef and month combinations. The months when less than the targeted number of samples were obtained occurred either at the start of the project, while participants were still being trained, or around the austral winter during prolonged periods of poor weather and sea-state. This shows that our participants were actively engaged in the project, but also the value in having as many volunteers as is practically and financially possible. Note however, unlike many citizen science projects, where participants use their own equipment (e.g. a smartphone) or are provided with online or printed material (Johnson and Johnston, 2013; Pecl et al., 2014; Jenkins et al., 2017; Tweedley et al., 2017), the current study had to supply volunteers with relatively expensive equipment, which limited participant numbers.

All volunteers recruited to Reef Vision were avid recreational fishers (20\% were also SCUBA divers) who lived in the vicinity of the reefs. Participants with these interests were sought out for the project, due to them being frequent users of the artificial reefs and thus able to deploy the BRUVs regularly, but also having extensive knowledge of the local conditions and commonly encountered fish species. Recruiting these types of volunteers increased engagement, thus reducing attrition and helped ensure the provision of regular videos and that safety was not compromised.

Although there has often been stigma about quality of the data provided by citizen science, as it is not collected by experts (Conrad and Daoust, 2008; Dickinson et al., 2010), the use of video prevents this issue influencing the resultant data. Thus, unlike observation counts (e.g. underwater visual census) and similar in situ data collection methods, video footage is able to be permanently archived and analysed by experts (as in the case of the current study) and any footage can be replayed and reanalysed in the future (Willis et al., 2000; Tessier et al., 2005; Mallet and Pelletier, 2014). 


\section{Soak time analyses}

For a faunal monitoring regime to be successful, it must provide accurate data on abundance of each species, whilst, at the same time, being relatively economical. Although many studies have cited the cost-effectiveness of BRUVs in comparison to visual surveys, mainly due to the reduction fieldwork time (e.g. Cappo et al., 2003; Watson et al., 2005; Langlois et al., 2010), the time required to extract the data from the video footage can be considerable (Francour et al., 1999; Stobart et al., 2007). An obvious way of reducing this cost is to decrease the soak time of the BRUV. However, Gladstone et al. (2012) showed that greater improvements in precision occurred from increasing soak time rather than replication. In the current study, a soak time of 45 minutes was found to provide a statistically robust estimation of the abundance, diversity and composition of the fish fauna of the artificial reefs in Geographe Bay.

Whitmarsh et al. (2017) in a meta-analysis of 161 BRUV studies found that cameras were deployed between 15 minutes and 120 minutes, with peaks in frequency of 30,60 and 90 minutes. While the value of 45 minutes calculated in the current study was similar to that recorded for demersal species in Hawaiian coastal waters (Misa et al., 2016), it is substantially greater than that for natural and artificial reefs in estuarine and marine waters of New South Wales (Folpp et al., 2013; Harasti et al., 2015). Differences in the length of soak time required are likely due to the diversity of species present at a site, with longer soak times needed in more diverse areas (James Tweedley, Murdoch University unpublished data) or in areas with very low and/or highly variable abundance of fish. This is the case in pelagic environments, where 120 minutes of soak times is often used and, even then, can produce zero inflated data (Santana-Garcon et al., 2014). While, comparative studies on soak time are rare, Harasti et al. (2015), showed that on temperate reefs in New South Wales, the MaxN for many reef-associated species occurred within 12.5 minutes, with this value rising to $30-40$ minutes on similar habitats in South Australia (Whitmarsh et al., 2017). This variability highlights the importance of determining for any monitoring regime, as in the current paper, the soak time required to generate statistically-robust data. Note that, in additional to elucidating how the number of species and total MaxN change over time (e.g. Stobart et al., 
2007; Gladstone et al., 2012; Santana-Garcon et al., 2014; Harasti et al., 2015; Misa et al., 2016) there is also value in, as in the current study, assessing how the faunal composition changes over time. This because while many studies focus on community rather than species level changes in abundance (e.g. Wakefield et al., 2013; Lowry et al., 2014), few demonstrate the effect soak time has on faunal composition.

\section{Differences in fish fauna among artificial reefs and seasons}

The results of univariate and multivariate analysis showed that the number of species, total MaxN and fish faunal composition differed significantly with Reef and Season and that Simpson's diversity index changed between reefs. Although not the main focus of this proof of concept study, this demonstrates that the sampling methodology employed by the citizen scientists can generate data of sufficient quality for use in statistical analyses. This was not the case with preliminary trials using cameras that provided a live video stream to the surface, where the resolution and quality of that video was too poor to adequately identify and count fish (Florisson, 2015; Tweedley et al., 2016a).

Although based on a relatively small suite of data, the trends reported in the current study mirror those found elsewhere, thus providing reassurance that the data generated are sound. For example, both the number of species and total MaxN differed among seasons, being greater during summer and winter, resulting in a change in species composition. This is thought to reflect an increase in water temperature in Geographe Bay during summer (McMahon et al., 1997). Such increases in temperature have been shown to similarly influence the fish communities of several artificial reefs around the world (Bohnsack et al., 1994; Relini et al., 1994; Mills et al., 2017; Rosemond et al., 2018).

When comparing between the two reefs, the number of species, total MaxN and Simpson's diversity index were all greater on the Dunsborough than Bunbury artificial reef. While these data are preliminary, their trends do match those obtained by Tweedley et al. (2016a) and could be due to the locations of the two reefs within Geographe Bay. The southwest edge of this embayment has a high level of reef connectivity, due to the number of 
limestone and granite reefs occurring near Cape Naturaliste. These natural reefs have been shown to significantly influence nearby fish communities (Westera et al., 2007) and have likely facilitated utilisation and colonisation of the near-by Dunsborough artificial reef by fishes. It is also noteworthy that data collected independently on the Bunbury and Dunsborough artificial reefs using Diver Operated Video and BRUVs demonstrate that the fish faunas of these two reefs are different (Paul Lewis, Department of Primary Industries and Regional Development, unpublished data).

\section{Effectiveness of the monitoring program and recommendations}

The effectiveness of the citizen science monitoring of the artificial reefs in this study was facilitated by the BRUV design. The frame was lightweight, durable and built to similar specifications as BRUVs in other scientific studies (e.g. Ellis and DeMartini, 1995; Willis and Babcock, 2000; Heagney et al., 2007), yet constructed for approximately a quarter of the cost of commercially-available equivalents (Table 4). The total cost of the Reef Vision program, including the development and production of 12 BRUVs, training of volunteers and salary to fund the part-time employment $(0.2 \mathrm{FTE})$ of a volunteer manager was $\sim \mathrm{AU} \$ 27,000$. The estimated costs of a University-led equivalent program, involving the purchase of four commercially-available BRUVs and the travel and salary costs of undertaking one fieldtrip per month to collected videos from each artificial reef, were almost $50 \%$ greater at $\sim$ AU $\$ 55,000$ (Table 4). Thus, in the case of the current study, employing a citizen science approach substantially reduced the cost of the project.

The use of an easy-to-use and commonly-owned small action camera, combined with in-person training made instances where volunteers required technical assistance minimal. This, together with the high resolution video produced, helped maintain participant engagement and reduced attrition. Engagement and management of volunteers was achieved via a closed group on Facebook containing 20 members (i.e. volunteers and project staff). On

this private page, participants could share videos and photographs from their stills, experiences, troubleshoot and engage with the project managers. Throughout the year long 
study, members wrote 169 posts, which were 'liked' 685 times and generated 526 comments. Volunteers felt that 'capturing' a fish on the camera was a form of fishing. Several of them produced 'highlight reels' from the footage they collected and uploaded these to open Facebook groups that were typically related to recreational fishing and, in some cases also YouTube. Participating in the Reef Vision program was seen by volunteers as a way to 'give back' to the community and exponents of fishing, thus creating feelings of satisfaction, contentment, sense of achievement, fulfilment, pride and happiness, whilst also increasing ownership and stewardship over the artificial reefs.

While we consider that the citizen science approach (Reef Vision) detailed here could be used to monitor the fauna of other artificial reefs, there are some ways in which the methodology could be improved. Firstly, a larger pool of suitable volunteers is recommended as this reduces the risk of limited data collection during periods of undesirable weather and sea-state. Such a repository of participants would also reduce the impact of any unforeseen volunteer attrition. In the case of the current study, we consider that eight (rather than six) volunteers would be appropriate for monitoring an artificial reef of the size of those in Geographe Bay (Fig. 1).

Many studies on the fish fauna of artificial reefs have focused on the changes in community composition that occurred post-deployment and, as such, contain no data on the faunal assemblage prior to the deployment of the structure (e.g. Bohnsack and Talbot, 1980; Duffy-Anderson et al., 2003; Burt et al., 2009; Folpp et al., 2011; Becker et al., 2017). This baseline data is vital if the performance of the reef is to be measured against its aims and objectives. In the case of the current study, this would require the engagement of community during the planning stages of the artificial reef to ensure a spatially and temporally robust set of data are collected as a baseline. It is noteworthy that both Diplock (2010) and Streich et al. (2017) recommend a Before-After-Control-Impact (BACI) monitoring approach be employed to help elucidate the influence a new reef deployment has on local fish assemblages. The choice of a control site is critical, however, as the results of several studies have determined that the characteristics of the fish fauna associated with artificial reefs can differ markedly 
from those of adjacent natural reefs (Thanner et al., 2006; Burt et al., 2009; Folpp et al., 2013).

\section{Conclusions}

This study has demonstrated that citizen science can be an effective tool for monitoring the fish faunas of artificial reefs. The use of recreational fishers to collect BRUV video samples, but having the resultant footage analysed and interpreted by professional scientists, lowers fieldwork costs, circumvents some of the stigma around citizen science and increases community engagement. Reef Vision volunteers were able to collect enough data of sufficient quality to monitor the Bunbury and Dunsborough artificial reefs in Geographe Bay, south-western Australia. These data were extracted from the footage and used in robust univariate and multivariate analyses to determine that a soak time of 45 minutes was sufficient to capture $95 \%$ of the diversity and community composition of the fish fauna and detect spatial and temporal differences in those fauna. With the continuing deployment of artificial reefs around the world, the use of citizen science in monitoring can provide valuable data for researchers, managers and decision makers. Projects such as Reef Vision can also benefit volunteers and communities by enhancing social values, creating ownership over research projects and fostering stewardship of aquatic resources.

\section{Acknowledgements}

Gratitude is expressed to the recreational fishers and divers who participated in the Reef Vison program and to Andrew Rowland, Leyland Campbell, Andrew Matthews, Mark Pagano, Paul Lewis, Howard Gill, Thomas Bateman, Michael Tropiano and Stephanie Watts for their support and advice during the project. Whiteys Tackle and Camping, Dunsborough Outdoor Sportz and Coastal Water Dive are thanked for supplying bait and providing logistical support. This project was supported by Recfishwest and Department of Primary Industries and Regional Development through funding from the Recreational Fishing Initiatives Fund, the Fisheries Research and Development Corporation (FRDC 2013/221) on 
behalf of the Australian Government and Murdoch University. This was conducted in accordance with Murdoch University Human Ethic Permit \#2014/2005 and Animal Ethics Permit \#O2626/14.

\section{References}

Aceves-Bueno, E., Adeleye, A., Bradley, D., Tyler Brandt, W., Callery, P., Feraud, M., Garner, K.L., Gentry, R., Huang, Y., McCullough, I., Pearlman, I., Sutherland, S.A., Wilkinson, W., Yang, Y., Zink, T., Anderson, S.E., Tague, C., 2015. Citizen science as an approach for overcoming insufficient monitoring and inadequate stakeholder buy-in in adaptive management: criteria and evidence. Ecosystems 18, 493-506.

Anderson, L.G., Chapman, J.K., Escontrela, D., Gough, C.L.A., 2017. The role of conservation volunteers in the detection, monitoring and management of invasive alien lionfish. Management of Biological Invasions 8, 589-598.

Anderson, M.J., Gorley, R.N., Clarke, K.R., 2008. PERMANOVA+ for PRIMER: guide to software and statistical methods. PRIMER-E, Plymouth, UK.

Australian Institute of Marine Science, 2017. Sea Water Temperature Logger Data at Geographe Bay, From 26 Nov 2014 To 19 Oct 2016.

Baine, M., 2001. Artificial reefs: a review of their design, application, management and performance. Ocean \& Coastal Management 44, 241-259.

Becker, K., Taylor, M.D., Lowry, M.B., 2017. Monitoring reef associated and pelagic fish communities on Australia's first purpose built offshore artificial reef. ICES Journal of Marine Science 74, 277-285.

Belda, M., Holtanová, E., Halenka, T., Kalvová, J., 2014. Climate classification revisited: from Köppen to Trewartha. Climate Research 59, 1-13.

Boakes, E.H., Gliozzo, G., Seymour, V., Harvey, M., Smith, C., Roy, D.B., Haklay, M., 2016. Patterns of contribution to citizen science biodiversity projects increase understanding of volunteers' recording behaviour. Scientific Reports 6, 33051.

Bohnsack, J.A., Talbot, F.H., 1980. Species-Packing by Reef Fishes on Australian and Caribbean Reefs:An Experimental Approach. Bulletin of Marine Science 30, 710-723.

Bohnsack, J.A., 1989. Are high densities of fishes at artificial reefs the result of habitat limitation or behavioral preference? Bulletin of Marine Science 44, 631-645.

Bohnsack, J.A., Johnson, D.L., Ambrose, R.F., 1991. Ecology of artificial reef habitats and fishes, in: Seaman, W. (Ed.), Artificial Habitats for Marine and Freshwater Fisheries. Academic Press, San Diego, USA., pp. 61-107.

Bohnsack, J.A., Harper, D.E., McClellan, D.B., Hulsbeck, M., 1994. Effects of reef size on colonization and assemblage structure of fishes at artificial reefs off southeastern Florida, U.S.A. Bulletin of Marine Science 55, 796-823.

Brickhill, M.J., Lee, S.Y., Connolly, R.M., 2005. Fishes associated with artificial reefs: Attributing changes to attraction or production using novel approaches. Journal of Fish Biology 67, 53-71.

Burt, J., Bartholomew, A., Usseglio, P., Bauman, A., Sale, P.F., 2009. Are artificial reefs surrogates of natural habitats for corals and fish in Dubai, United Arab Emirates? Coral Reefs 28, 663-675.

Cappo, M.C., Harvey, E.S., Malcolm, H.A., Speare, P.J., 2003. Potential of video techniques to monitor diversity, abundance and size of fish in studies of marine protected areas, in: 
Beumer, J.P., Grant, A., Smith, D.C. (Eds.), Aquatic Protected Areas-what works best and how do we know? Australian Society of Fish Biology, Cairns, Australia.

Chase, S.K., Levine, A., 2016. A framework for evaluation and designing citizen science programs for natural resources monitoring. Conservation Biology 30, 456-466.

Cigliano, J.A., Meyer, R., Ballard, H.L., Freitag, A., Phillips, T.B., Wasser, A., 2015. Making marine and coastal citizen science matter. Ocean and Coastal Management 115, 77-87.

Clarke, K.R., Green, R.H., 1988. Statistical design and analysis for a 'biological effects' study. Marine Ecology Progress Series 46, 213-226.

Clarke, K.R., 1993. Non-parametric multivariate analyses of changes in community structure. Australian Journal of Ecology 18, 117-143.

Clarke, K.R., Chapman, M.G., Somerfield, P.J., Needham, H.R., 2006. Dispersion-based weighting of species counts in assemblage analyses. Marine Ecology Progress Series $320,11-27$.

Clarke, K.R., Gorley, R.N., Somerfield, P.J., Warwick, R.M., 2014a. Change in Marine Communities: an Approach to Statistical Analysis and Interpretation, 3 ed. PRIMER-E Ltd, Plymouth, UK.

Clarke, K.R., Tweedley, J.R., Valesini, F.J., 2014b. Simple shade plots aid better long-term choices of data pre-treatment in multivariate assemblage studies. Journal of the Marine Biological Association of the United Kingdom 94, 1-16.

Clarke, K.R., Gorley, R.N., 2015. PRIMER v7: User Manual/Tutorial. PRIMER-E, Plymouth.

Coll, J., Moranta, J., Reñones, O., García-Rubies, A., Moreno, I., 1998. Influence of substrate and deployment time on fish assemblages on an artificial reef at Formentera Island (Balearic Islands, western Mediterranean). Hydrobiologia 385, 139-152.

Conrad, C.T., Daoust, T., 2008. Community-Based Monitoring Frameworks: Increasing the Effectiveness of Environmental Stewardship. Environmental Management 41, 358-366.

Cresson, P., Ruitton, S., Harmelin-Vivien, M., 2014. Artificial reefs do increase secondary biomass production: mechanisms evidenced by stable isotopes. Marine Ecology Progress Series 509, 15-26.

Department of Fisheries, 2012. Policy on habitat enhancement structures in Western Australia. Department of Fisheries, Perth, Australia.

Department of the Environment, 2016. Artificial reefs.

Dickinson, J.L., Zuckerberg, B., Bonter, D.N., 2010. Citizen science as an ecological research tool: Challenges and benefits. Annual Review of Ecology, Evolution, and Systematics 41, 149-172.

Dickinson, J.L., Shirk, J., Bonter, D., Bonney, R., Crain, R.L., Martin, J., Phillips, T., Purcell, K., 2012. The current state of citizen science as a tool for ecological research and public engagement. Frontiers in Ecology and the Environment 10, 291-297.

Diplock, J., 2010. Artificial Reefs - Design and Monitoring Standards Workshops. Fisheries Research and Development Corporation, Summer Hill, NSW.

Dorman, S., Harvey, E., Newman, S., 2012. Bait effects in sampling coral reef fish assemblages with stereo-BRUVs. PLoS ONE 7, e41538.

dos Santos, L.N., Zalmon, L.R., 2015. Long-term changes of fish assemblages associated with artificial reefs off the northern coast of Rio de Janeiro, Brazil. Journal of Applied Ichthyology 31, 15-23.

Duffy-Anderson, J.T., Manderson, J.P., Able, K.W., 2003. A characterization of juvenile fish assemblages around man-made structures in the New York\&\#8211;New Jersey Harbor estuary, U.S.A. Bulletin of Marine Science 72, 877-889.

Dunn, R.J.K., Zigic, S., Sheill, G.R., 2014. Modelling the disperson of treated wastewater in a shallow wind-driven environment, Geographe Bay, Western Australia: implications 
for environmental management. Environmental Monitoring and Assessment 186, 61076125.

Ellis, D., DeMartini, E., 1995. Evaluation of a video camera technique for indexing abundances of juvenile pink snapper, Pristipomoides filamentosus, and other Hawaiian insular shelf fishes. Fishery Bulletin 93, 67-77.

Fabi, G., Scarcella, G., Spagnolo, A., Bortone, S.A., Charbonnel, E., Goutayer, J.J., Haddad, N., Lok, A., Trommelen, M., 2015. Practical Guidelines for the Use of Artificial Reefs in the Mediterranean and Black Sea. . Food and Agriculture Organization of the United Nations, Rome, Italy.

Fahrner, C.K., Pattiaratchi, C.B., 1995. The physical oceanography of Geographe Bay, Western Australia, in: Lord, D.A. (Ed.), Geographe Bay Summary Report, Wastewater 2040 Strategy for the South-West Region. Water Authority of Western Australia, , Perth, Western Australia, pp. 3-12.

Fairclough, D.V., Brown, J.I., Carlish, B.J., Crisafulli, B.M., Keay, I.S., 2014. Breathing life into fisheries stock assessment with citizen science. Scientific Reports 4, 7249.

Florisson, J.H., 2015. Can recreational fishers provide an effective means of monitoring artificial reefs? Murdoch University, Perth, Western Australia.

Follett, R., Strezov, V., 2015. An Analysis of Citizen Science Based Research: Usage and Publication Patterns. PLOS ONE 10, e0143687.

Folpp, H., Lowry, M., Gregson, M., Suthers, I.M., 2011. Colonization and community development of fish assemblages associated with estuarine artificial reefs. Brazilian Journal of Oceanography 59, 55-67.

Folpp, H., Lowry, M., Gregson, M., Suthers, I.M., 2013. Fish assemblages on estuarine artificial reefs: natural rocky-reef mimics or discrete assemblages. PLoS ONE 8, e63505.

Francour, P., Liret, C., Harvey, E., 1999. Comparison of fish abundance estimates made by remote underwater video and visual census. Naturalista Siciliana XXIII, 155-168.

Gentilli, J., 1971. World Survey of Climatology. Volume 13. Climate of Australia and New Zealand. Elsevier Publishing Company., Amsterdam.

Gladstone, W., Lindfield, S., Coleman, M., Kelaher, B., 2012. Optimisation of baited remote underwater video sampling designs for estuarine fish assemblages. Journal of Experimental Marine Biology and Ecology 429, 28-35.

Goetze, J., Langlois, T., Egli, D., Harvey, E., 2011. Evidence of artisanal fishing impacts and depth refuge in assemblages of Fijian reef fish. Coral Reefs 30, 1-11.

Harasti, D., Malcolm, H., Gallen, C., Coleman, M.A., Jordan, A., Knott, N.A., 2015. Appropriate set times to represent patterns of rocky reef fishes using baited video. Journal of Experimental Marine Biology and Ecology 463, 173-180.

Heagney, E.C., Lynch, T.P., Babcock, R.C., Suthers, I.M., 2007. Pelagic fish assemblages assessed using mid-water baited videostandardising fish counts using bait plume size. Marine Ecology Progress Series 350, 255-266.

International Maritime Organization, 2016. Convention on the prevention of marine pollution by dumping of wastes and other matter.

Jenkins, G.I., Tweedley, J.R., Trayler, K.M., 2017. Re-establishing recreational prawning in the Swan-Canning Estuary. Western Australian Fish Foundation, Perth, Western Australia, p. 128.

Johnson, Z.I., Johnston, D.W., 2013. Smartphones: Powerful Tools for Geoscience Education. Eos, Transactions American Geophysical Union 94, 433-434.

Jordan, K.B., Gilliam, D.S., Spieler, R.E., 2005. Reef fish assemblage structure affected by small-scale spacing and size variations of artificial patch reefs. Journal of Experimental Marine Biology and Ecology 326, 170-186. 
Langlois, T.J., Harvey, E.S., Fitzpatrick, B., Meeuwig, J.J., Shedrawi, G., Watson, D.L., 2010. Cost-efficient sampling of fish assemblages: Comparison of baited video stations and diver video transects. Aquatic Biology 9, 155-168.

Lek, E., Fairclough, D.V., Platell, M.E., Clarke, K.R., Tweedley, J.R., Potter, I.C., 2011. To what extent are the dietary compositions of three abundant, co-occurring labrid species different and related to latitude, habitat, body size and season? Journal of Fish Biology 78, 1913-1943.

Lowry, M.B., Glasby, T.M., Boys, C.A., Folpp, H., Suthers, I., Gregson, M., 2014. Response of fish communities to the deployment of estuarine artificial reefs for fisheries enhancement. Fisheries Management and Ecology 21, 42-56.

Mallet, D., Pelletier, D., 2014. Underwater video techniques for observing coastal marine biodiversity; A review of sixty years of publications (1952-2012). Fisheries Research $154,44-62$.

McKinley, D.C., Miller-Rushing, A.J., Ballard, H.L., Bonney, R., Brown, H., Cook-Patton, S.C., Evans, D.M., French, R.A., Parrish, J.K., Phillips, T.B., Ryan, S.F., Shanley, L.A., Shirk, J.L., Stepenuck, K.F., Weltzin, J.F., Wiggins, A., Boyle, O.D., Briggs, R.D., Chapin, S.F., Hewitt, D.A., Preuss, P.W., Soukup, M.A., 2017. Citizen science can improve conservation science, natural resource management, and environmental protection. Biological Conservation 208, 15-28.

McMahon, K., Young, E., Montgomery, S., Cosgrove, J., Wilshaw, J., Walker, D.I., 1997. Status of a shallow seagrass system, Geographe Bay, south-western Australia. Journal of the Royal Society of Western Australia 80, 155-262.

Mills, K.A., Hamer, P.A., Quinn, G.P., 2017. Artificial reefs create distinct fish assemblages. Marine Ecology Progress Series 585, 155-173.

Misa, W.F.X.E., Richards, B.L., DiNardo, G.T., Kelley, C.D., Moriwake, V.N., Drazen, J.C., 2016. Evaluating the effect of soak time on bottomfish abundance and length data from stereo-video surveys. Journal of Experimental Marine Biology and Ecology 479, 20-34.

Pecl, G., Barry, Y., Brown, R., Frusher, S., Gartner, E., Pender, A., Robinson, L., Walsh, P., Stuart-Smith, J., 2014. REDMAP: Ecological monitoring and community engagement through citizen science. The Tasmanian Naturalist 136, 158-164.

Potter, I.C., Veale, L.J., Tweedley, J.R., Clarke, K.R., 2016. Decadal changes in the ichthyofauna of a eutrophic estuary following a remedial engineering modification and subsequent environmental shifts. Estuarine, Coastal and Shelf Science 181, 345-363.

Recfishwest, 2017. Reef Vision - Artificial Reef Monitoring.

Relini, G., Relini, M., Torchia, G., Palandri, G., 2002. Ten years of censuses of fish fauna on the Loano artificial reef. ICES Journal of Marine Science 59, S132-S137.

Relini, M., Torchia, G., Relini, G., 1994. Seasonal variation of fish assemblages in the Loano artificial reef (Ligurian Sea northwestern-Mediterranean). Bulletin of Marine Science 55, 401-417.

Rosemond, R.C., Paxton, A.B., Lemoine, H.R., Fegley, S.R., Peterson, C.H., 2018. Fish use of reef structures and adjacent sand flats: implications for selecting minimum buffer zones between new artificial reefs and existing reefs. Marine Ecology Progress Series 587, 187-199.

Santana-Garcon, J., Newman, S.J., Harvey, E.S., 2014. Development and validation of a midwater baited stereo-video technique for investigating pelagic fish assemblages. Journal of Experimental Marine Biology and Ecology 452, 82-90.

Scott, M.E., Smith, J.A., Lowry, M.B., Taylor, M.D., Suthers, I.M., 2015. The influence of an offshore artificial reef on the abundance of fish in the surrounding pelagic environment. Marine and Freshwater Research 66, 429-437. 
Seaman, W., Jensen, A.C., 2000. Purposes and practices of artificial reef evaluation, in: Seaman, W. (Ed.), Artificial Reef Evaluation: With Application to Natural Marine Habitats. CRC Press, Boca Raton, U.S.A, pp. 2-17.

Seaman, W., 2007. Artificial habitats and the restoration of degraded marine ecosystems and fisheries. Hydrobiologia 580, 143-155.

Silvertown, J., 2009. A new dawn for citizen science. Trends in Ecology \& Evolution 24, 467-471.

Smith, J.A., Lowry, M.B., Champion, C., Suthers, I.M., 2016. A designed artificial reef is among the most productive marine fish habitats: new metrics to address 'production versus attraction'. Marine Biology 163, 188.

Stobart, B., García-Charton, J.A., Espejo, C., Rochel, E., Goñi, R., Reñones, O., Herrero, A., Crec'hriou, R., Polti, S., Marcos, C., Planes, S., Pérez-Ruzafa, A., 2007. A baited underwater video technique to assess shallow-water Mediterranean fish assemblages: Methodological evaluation. Journal of Experimental Marine Biology and Ecology 345, 158-174.

Stobart, B., Diaz, D., F., A., Alonso, C., S., M., Goni, R., 2015. Performance of baited underwater video: does it underestimate abundance at high population densities. PLoS ONE 10, e0127559.

Streich, M.K., Ajemian, M.J., Wetz, J.J., Shively, J.D., Shipley, J.B., Stunz, G.W., 2017. Effects of a New Artificial Reef Complex on Red Snapper and the Associated Fish Community: an Evaluation Using a Before-After Control-Impact Approach. Marine and Coastal Fisheries 9, 404-418.

Sutton, S.G., Bushnell, S.L., 2007. Socio-economic aspects of artificial reefs: Considerations for the Great Barrier Reef Marine Park. Ocean and Coastal Management 50, 829-846.

Tessier, E., Chabanet, P., Pothin, K., Soria, M., Lasserre, G., 2005. Visual censuses of tropical fish aggregations on artificial reefs: slate versus video recording techniques. Journal of Experimental Marine Biology and Ecology 315, 17-30.

Thanner, S.E., McIntosh, T.L., Blair, S.M., 2006. Development of benthic and fish assemblages on artificial reef materials compared to adjacent natural reef assemblages in Miami-Dade County, Florida. Bulletin of Marine Science 78, 57-70.

Thiel, M., Penna-Diaz, M.A., G., L.-J., Salas, S., Sellanes, J., Stotz, W., 2014. Citizen scientists and marine research: volunteer participants, their contributions and projection for the future. Oceanography and Marine Biology: An Annual Review 52, 257-314.

Thompson, A.A., Mapstone, B.D., 1997. Observer effects and training in underwater visual surveys of reef fishes. Marine Ecology Progress Series 154, 53-63.

Tweedley, J.R., Florisson, J.H., Bateman, T.A., Chaplin, J.A., Gill, H.S., 2016a. Can recreational fishers provide a cost effective means for monitoring artificial reefs? Murdoch University, Perth, Western Australia, p. 208.

Tweedley, J.R., Warwick, R.M., Potter, I.C., 2016b. The contrasting ecology of temperate macrotidal and microtidal estuaries. Oceanography and Marine Biology: An Annual Review 54, 73-171.

Tweedley, J.R., Loneragan, N.R., Crisp, J.A., Poh, B., Broadley, A.D., Bennett, A.L., Hodson, K.P., Trayler, K.M., Jenkins, G.I., Chaplin, J.A., 2017. Stock enhancement of the Western School Prawn (Metapenaeus dalli) in the Swan-Canning Estuary; evaluating recruitment limitation, environment and release strategies. Report for the Fisheries Research and Development Corporation, Murdoch University, Perth, Western Australia, p. 546.

Ugland, K.I., Gray, J.S., Ellingsen, K.E., 2003. The species-accumulation curve and estimation of species richness. Journal of Animal Ecology 72, 888-897. 
Van Niel, K.P., Holmes, K.W., Radford, B., 2009. Seagrass Mapping Geographe Bay 2004 2007. Report to the Southwest Catchment Council, Perth, Western Australia, pp. 1-25.

Veale, L., Tweedley, J.R., Clarke, K.R., Hallett, C.S., Potter, I.C., 2014. Characteristics of the ichthyofauna of a temperate microtidal estuary with a reverse salinity gradient, including inter-decadal comparisons. Journal of Fish Biology 85, 1320-1354.

Wakefield, C.B., Lewis, P.D., Coutts, T.B., Fairclough, D.V., Langlois, T.J., 2013. Fish Assemblages Associated with Natural and Anthropogenically-Modified Habitats in a Marine Embayment: Comparison of Baited Videos and Opera-House Traps. PLOS ONE 8, e59959.

Watson, D., Harvey, E., Fitzpatrick, B., Langlois, T., Shedrawi, G., 2010. Assessing reef fish assemblage structure: how do different stereo-video techniques compare? Marine Biology 157, 1237-1250.

Watson, D.L., Harvey, E.S., Anderson, M.J., Kendrick, G.A., 2005. A comparison of temperate reef fish assemblages recorded by three underwater stereo-video techniques. Marine Biology 148, 415-425.

Westera, M.B., Barnes, P., Kendrick, G.A., Cambridge, M., 2007. Establishing benchmarks of seagrass communities and water quality in Geographe Bay, Western Australia. Annual report to the South West Catchments Council., Perth, Australia, p. 67.

Whitmarsh, S.K., Fairweather, P.G., Huveneers, C., 2017. What is Big BRUVver up to? Methods and uses of baited underwater video. Reviews in Fish Biology and Fisheries 27, 53-73.

Willis, T., Babcock, R.C., 2000. A baited underwater video system for the determination of relative density of carnivorous reef fish. Marine and Freshwater Research 51, 755-763.

Willis, T.J., Millar, R.B., Babcock, R.C., 2000. Detection of spatial variability in relative density of fishes: Comparison of visual census, angling, and baited underwater video. Marine Ecology Progress Series 198, 249-260. 
Table 1. The total number of videos ( $>1 \mathrm{~h}$ in length) received from Reef Vision volunteers for each of the Bunbury and Dunsborough artificial reefs in each month between October 2015 and September 2016.

\begin{tabular}{lrrrrrrrrrrrrr}
\hline Artificial reef & Oct & Nov & Dec & Jan & Feb & Mar & Apr & May & Jun & Jul & Aug & Sep & Total \\
\hline Bunbury & 3 & 14 & 5 & 8 & 7 & 6 & 4 & 5 & 1 & 5 & 1 & 5 & $\mathbf{5 9}$ \\
Dunsborough & 5 & 4 & 7 & 8 & 6 & 6 & 4 & 5 & 2 & 5 & 4 & 1 & $\mathbf{5 2}$ \\
\hline Total & $\mathbf{8}$ & $\mathbf{1 8}$ & $\mathbf{1 2}$ & $\mathbf{1 6}$ & $\mathbf{1 3}$ & $\mathbf{1 2}$ & $\mathbf{8}$ & $\mathbf{1 0}$ & $\mathbf{3}$ & $\mathbf{1 0}$ & $\mathbf{5}$ & $\mathbf{6}$ & $\mathbf{1 1 1}$ \\
\hline
\end{tabular}


Table 2. Mean MaxN abundance $(\mathrm{N})$, standard error (SE), percentage contribution (\%), cumulative percentage contribution $(\mathrm{C} \%)$ of each species from the 24 videos recorded by BRUVs on the Bunbury and Dunsborough artificial reefs between October 2015 and September 2016. The number of videos in which each species was recorded (F) and the frequency of occurrence $(\% \mathrm{~F})$ are also provided, as it the family to which each species belongs. Species representing $>5 \%$ in terms of $\%$ or $\% \mathrm{~F}$ are highlighted in grey. $*$ denotes that a species is targeted by recreational fishers.

\begin{tabular}{|c|c|c|c|c|c|c|c|}
\hline \multirow[b]{2}{*}{ Species } & \multirow[b]{2}{*}{ Family } & \multicolumn{4}{|c|}{ Abundance } & \multicolumn{2}{|c|}{ Occurrence } \\
\hline & & $\mathbf{N}$ & SE & $\%$ & $\mathrm{C} \%$ & $\mathbf{F}$ & $\% \mathbf{F}$ \\
\hline Parapriacanthus elongatus & Pempheridae & 21.21 & 18.80 & 29.51 & 29.51 & 2 & 8.33 \\
\hline Neatypus obliquus & Kyphosidae & 9.46 & 2.31 & 13.16 & 42.67 & 15 & 62.50 \\
\hline Pseudocaranx spp.* & Carangidae & 8.75 & 2.98 & 12.17 & 54.84 & 18 & 75.00 \\
\hline Coris auricularis & Labridae & 8.17 & 1.27 & 11.36 & 66.20 & 22 & 91.67 \\
\hline Trachurus novaezelandiae & Carangidae & 8.00 & 6.92 & 11.13 & 77.33 & 2 & 8.33 \\
\hline Seriola hippos* & Carangidae & 2.88 & 1.06 & 4.00 & 81.33 & 20 & 83.33 \\
\hline Parequula melbournensis & Gerreidae & 1.83 & 0.42 & 2.55 & 83.88 & 15 & 62.50 \\
\hline Pempheris klunzingeri & Pempheridae & 1.71 & 1.01 & 2.38 & 86.26 & 3 & 12.50 \\
\hline Anoplocapros amygdaloides & Aracanidae & 1.83 & 0.34 & 2.55 & 88.81 & 19 & 79.17 \\
\hline Austrolabrus maculatus & Labridae & 1.13 & 0.33 & 1.57 & 90.38 & 10 & 41.67 \\
\hline Diodon nicthemerus & Diodontidae & 0.58 & 0.46 & 0.81 & 91.19 & 3 & 12.50 \\
\hline Chelmonops curiosus & Chaetodontidae & 0.67 & 0.17 & 0.93 & 92.12 & 11 & 45.83 \\
\hline Parapercis haackei & Pinguipedidae & 0.46 & 0.12 & 0.64 & 92.75 & 10 & 41.67 \\
\hline Myliobatus australis & Myliobatidae & 0.58 & 0.13 & 0.81 & 93.57 & 12 & 50.00 \\
\hline Trygonorrhina fasciata & Rhinobatidae & 0.54 & 0.15 & 0.75 & 94.32 & 10 & 41.67 \\
\hline Pentaceropsis recurvirostris* & Pentacerotidae & 0.33 & 0.14 & 0.46 & 94.78 & 5 & 20.83 \\
\hline Arripis truttaceus* & Arripidae & 0.25 & 0.25 & 0.35 & 95.13 & 1 & 4.17 \\
\hline Cheilodactylus gibbosus & Cheilodactylidae & 0.29 & 0.11 & 0.41 & 95.54 & 6 & 25.00 \\
\hline Glaucosoma hebraicum* & Glaucosomatidae & 0.21 & 0.08 & 0.29 & 95.83 & 5 & 20.83 \\
\hline Choerodon rubescens* & Labridae & 0.25 & 0.09 & 0.35 & 96.17 & 6 & 25.00 \\
\hline Anoplocapros lenticularis & Aracanidae & 0.21 & 0.08 & 0.29 & 96.46 & 5 & 20.83 \\
\hline Chromis westaustralis & Pomacentridae & 0.17 & 0.17 & 0.23 & 96.70 & 1 & 4.17 \\
\hline Monocanthidae spp. & Monocanthidae & 0.29 & 0.09 & 0.41 & 97.10 & 7 & 29.17 \\
\hline Suezichthys cyanolaemus & Labridae & 0.21 & 0.08 & 0.29 & 97.39 & 5 & 20.83 \\
\hline Parapercis ramsayi & Pinguipedidae & 0.21 & 0.08 & 0.29 & 97.68 & 5 & 20.83 \\
\hline Dasyatis brevicaudata & Dasyatidae & 0.21 & 0.08 & 0.29 & 97.97 & 5 & 20.83 \\
\hline Chaetodon assarius & Chaetodontidae & 0.13 & 0.09 & 0.17 & 98.14 & 2 & 8.33 \\
\hline Notolabrus parilus & Labridae & 0.13 & 0.07 & 0.17 & 98.32 & 3 & 12.50 \\
\hline Tilodon sexfasciatus & Kyphosidae & 0.17 & 0.08 & 0.23 & 98.55 & 4 & 16.67 \\
\hline Chrysophrys auratus* & Sparidae & 0.17 & 0.12 & 0.23 & 98.78 & 2 & 8.33 \\
\hline Pempherididae spp. & Pempherididae & 0.08 & 0.08 & 0.12 & 98.90 & 1 & 4.17 \\
\hline Upeneichthys vlamingii & Mullidae & 0.08 & 0.06 & 0.12 & 99.01 & 2 & 8.33 \\
\hline Trygonoptera mucosa & Urolophidae & 0.08 & 0.06 & 0.12 & 99.13 & 2 & 8.33 \\
\hline Platycephalus longispinis* & Platycephalidae & 0.08 & 0.06 & 0.12 & 99.25 & 2 & 8.33 \\
\hline Aptychotrema vincentiana & Rhinobatidae & 0.13 & 0.07 & 0.17 & 99.42 & 3 & 12.50 \\
\hline Trygonoptera personata & Urolophidae & 0.08 & 0.06 & 0.12 & 99.54 & 2 & 8.33 \\
\hline Eubalichthys mosaicus & Monacanthidae & 0.04 & 0.04 & 0.06 & 99.59 & 1 & 4.17 \\
\hline Apogon victoriae & Apogonidae & 0.04 & 0.04 & 0.06 & 99.65 & 1 & 4.17 \\
\hline Orectolobus maculatus & Orectolobidae & 0.04 & 0.04 & 0.06 & 99.71 & 1 & 4.17 \\
\hline Enoplosus armatus & Enoplosidae & 0.04 & 0.04 & 0.06 & 99.77 & 1 & 4.17 \\
\hline Notolabrus angustipes & Labridae & 0.04 & 0.04 & 0.06 & 99.83 & 1 & 4.17 \\
\hline Aracana aurita & Aracanidae & 0.04 & 0.04 & 0.06 & 99.88 & 1 & 4.17 \\
\hline Mustelus antarcticus* & Triakidae & 0.04 & 0.04 & 0.06 & 99.94 & 1 & 4.17 \\
\hline Achoerodus gouldii* & Labridae & 0.04 & 0.04 & 0.06 & 100.00 & 1 & 4.17 \\
\hline
\end{tabular}


Table 3. Mean squares (MS), percentage of the MS to the total (\%MS), pseudo-F $(p F)$ and significant level $(P)$ for two-way PERMANOVAs tests on the (a) number of species, (b) total MaxN, (c) Simpson's diversity index and the fish faunal composition of the two artificial reefs in the two seasons. Significant differences are highlighted in bold. $d f=$ degrees of freedom.

\begin{tabular}{|c|c|c|c|c|c|}
\hline (a) Number of species & $d f$ & MS & $\% M S$ & $p F$ & $P$ \\
\hline Reef & 1 & 96.00 & 50.63 & 6.80 & 0.026 \\
\hline Season & 1 & 73.50 & 38.76 & 5.21 & 0.034 \\
\hline Reef $^{\times}$Season & 1 & 6.00 & 3.16 & 0.43 & 0.516 \\
\hline Residual & 20 & 14.12 & 7.45 & & \\
\hline (b) Max & df & MS & $\% M S$ & $p F$ & $\boldsymbol{P}$ \\
\hline Reef & 1 & 10.07 & 65.88 & 22.76 & 0.001 \\
\hline Season & 1 & 4.13 & 27.03 & 9.34 & 0.005 \\
\hline Reef $^{\times}$Season & 1 & 0.64 & 4.19 & 1.45 & 0.256 \\
\hline Residual & 20 & 0.44 & 2.89 & & \\
\hline (c) Simp & df & MS & $\% M S$ & $p F$ & $P$ \\
\hline Reef & 1 & 0.13 & 61.91 & 5.96 & 0.022 \\
\hline Season & 1 & 0.06 & 27.54 & 2.65 & 0.119 \\
\hline Reef $^{\times}$Season & 1 & 0.00 & 0.18 & 0.02 & 0.892 \\
\hline Residual & 20 & 0.02 & 10.38 & & \\
\hline (d) Faunal con & df & MS & $\% M S$ & $p F$ & $P$ \\
\hline Reef & 1 & 3560 & 24.23 & 1.95 & 0.036 \\
\hline Season & 1 & 5955 & 40.53 & 3.26 & 0.003 \\
\hline Reef $^{\times}$Season & 1 & 3348 & 22.79 & 1.83 & 0.065 \\
\hline Residual & 20 & 1829 & 12.45 & & \\
\hline
\end{tabular}


Table 4. Approximate cost (AU\$) of running the Reef Vision program with 12 volunteers (6 per artificial reef) compared to the estimated cost of a science equivalent program run by an Australian university. The science equivalent cost is based on a team of two research assistants using a boat and four BRUVs to collect four videos from each artificial once a month for a year. Note that neither budget includes the cost of video processing and data extraction and analyses, which should be comparable for both programs.

\begin{tabular}{lrr}
\hline \multicolumn{1}{c}{ Costs } & Reef Vision & \multicolumn{2}{c}{ Science equivalent } \\
\hline Operating & & \\
BRUV frame & $\$ 5,172$ & $\$ 6,660$ \\
& $(12$ units $)$ & $(4$ units $)$ \\
BRUV cameras & $\$ 3,828$ & $\$ 1,276$ \\
& $(12$ units $)$ & $(4$ units $)$ \\
Bait & $\$ 1,440$ & $\$ 1,440$ \\
Consumables & $\$ 588$ & $\$ 2,400$ \\
Travel & & \\
Training workshop & $\$ 610$ & $\$ 0$ \\
Fieldwork & $\$ 0$ & $\$ 21,870$ \\
Salary & & \\
Volunteer management & $\$ 16,000$ & $\$ 0$ \\
Fieldwork & $\$ 0$ & $\$ 21,600$ \\
\hline Total & $\mathbf{\$ 2 7 , 6 3 8}$ & $\mathbf{\$ 5 5 , 2 4 6}$ \\
\hline
\end{tabular}




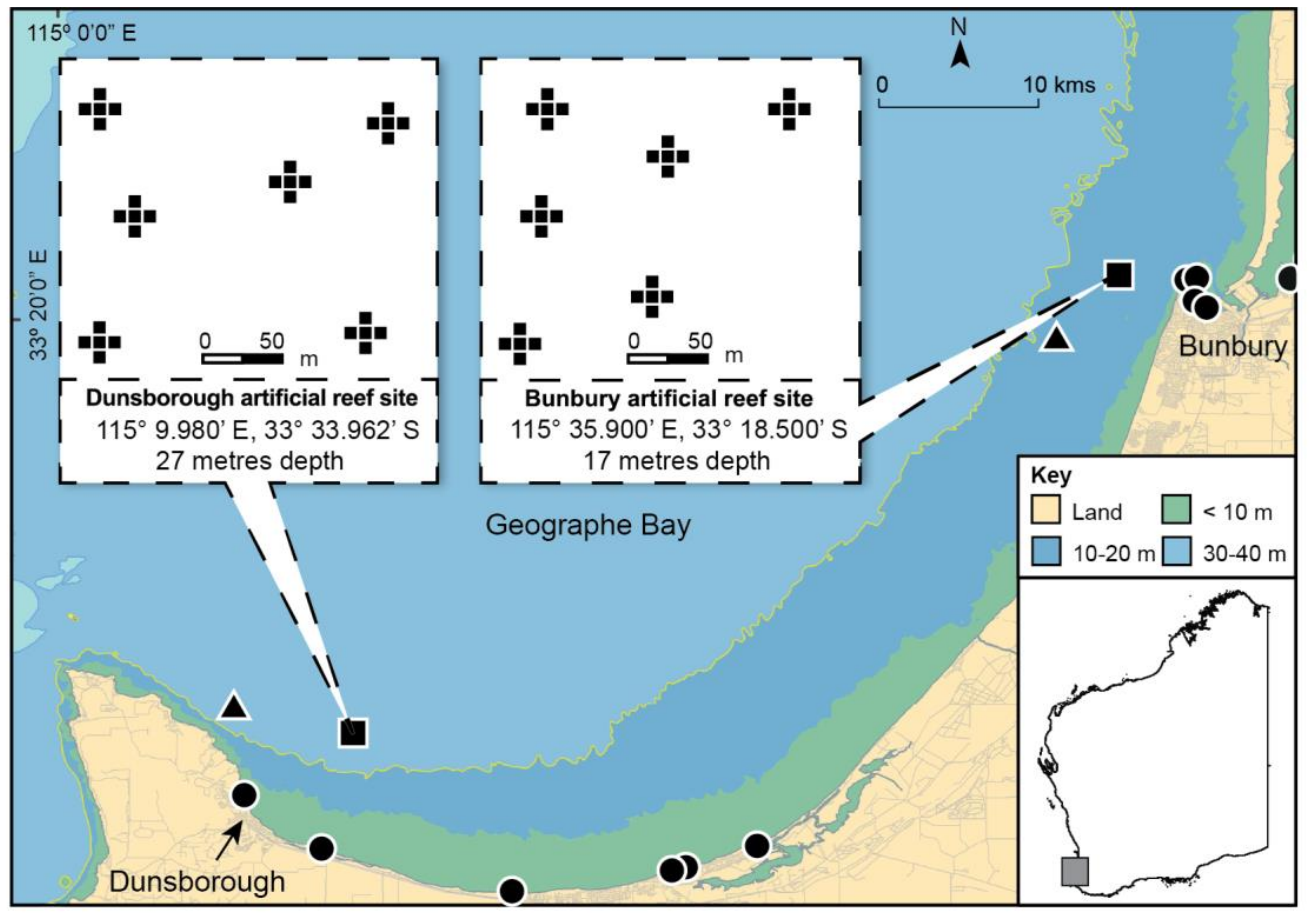

Fig. 1. Map showing the location of the Bunbury and Dunsborough artificial reefs in Geographe Bay and the configuration of their 30 concrete FishBox modules into six clusters. Grey square on inset denotes the location of Geographe Bay in Western Australia. purpose-built concrete reef; $\boldsymbol{\Delta}$ sunken ship artificial reef; $\boldsymbol{\bullet}$, boat ramp. Map modified from the Department of Primary Industries and Regional Development. 


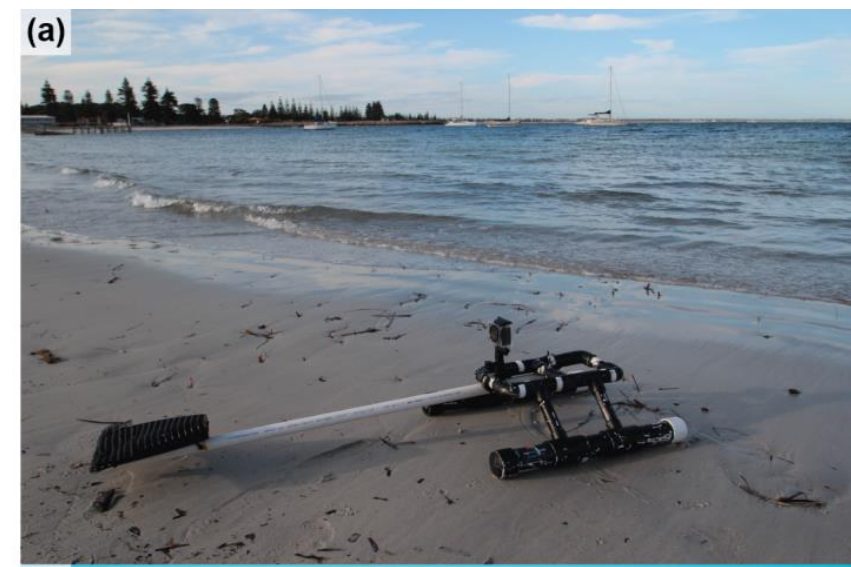

(b)

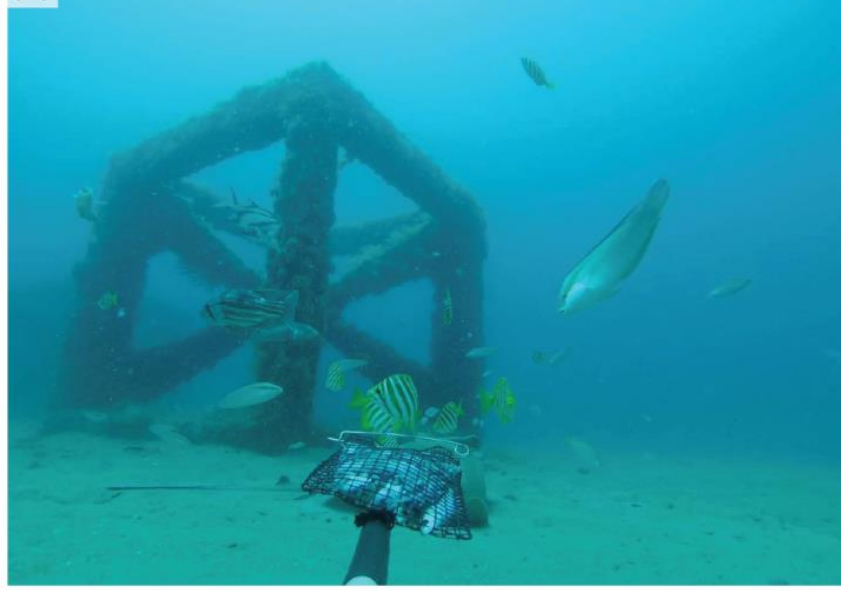

Fig. 2. Photographs of (a) the baited remote underwater video system supplied to Reef Vision participants and (b) a screenshot of footage collected from the Dunsborough artificial reef using the BRUV in (a). Footage in b shows 10 Coris auricularis, 10 Neatypus obliquus, 2 Pseudocaranx spp., 1 Pentaceropsis recurvirostris, 1 Glaucosoma hebraicum and 1 Myliobatis australis. 
(a)

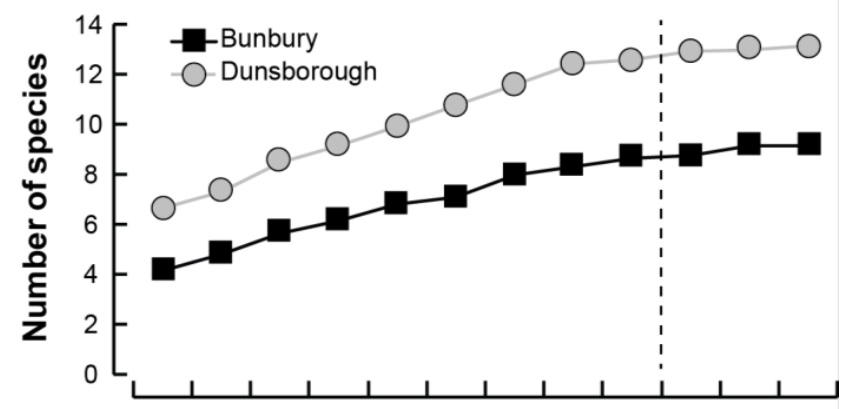

(b)

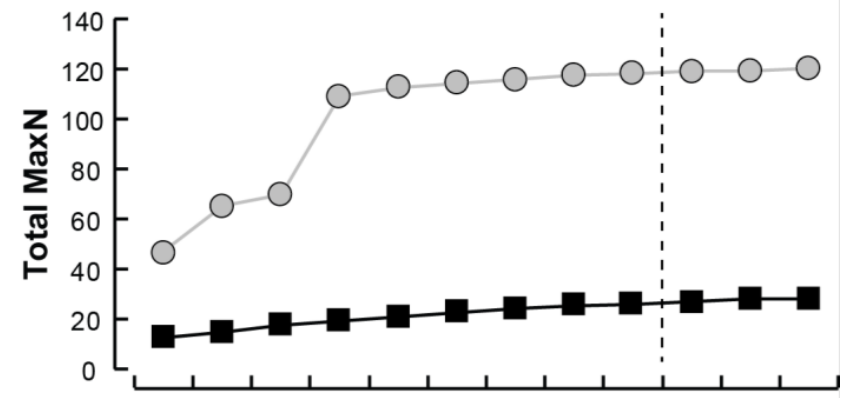

(c)

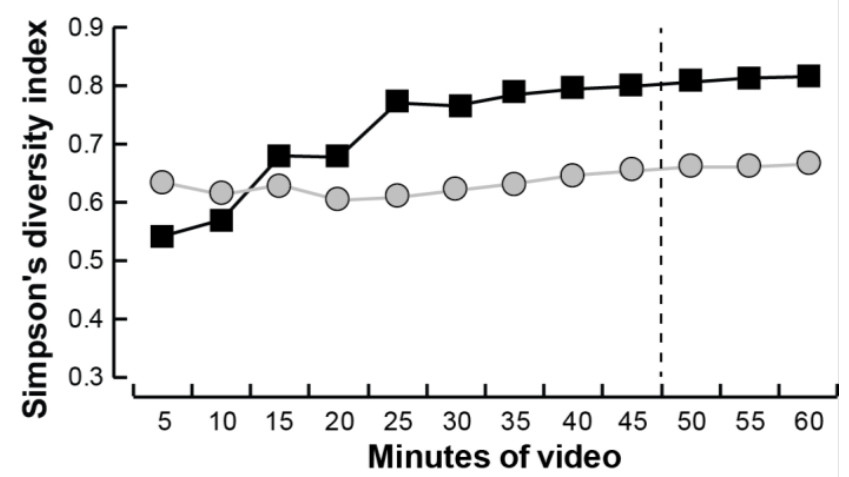

Fig. 3. Rarefaction curves for the (a) mean number of species, (b) total MaxN and (c) Simpson's diversity index from consecutive five minute intervals of BRUV footage recorded from the Bunbury and Dunsborough artificial reefs between October 2015 and September 2016. Vertical dashed line denotes 45 minutes. 
(a)
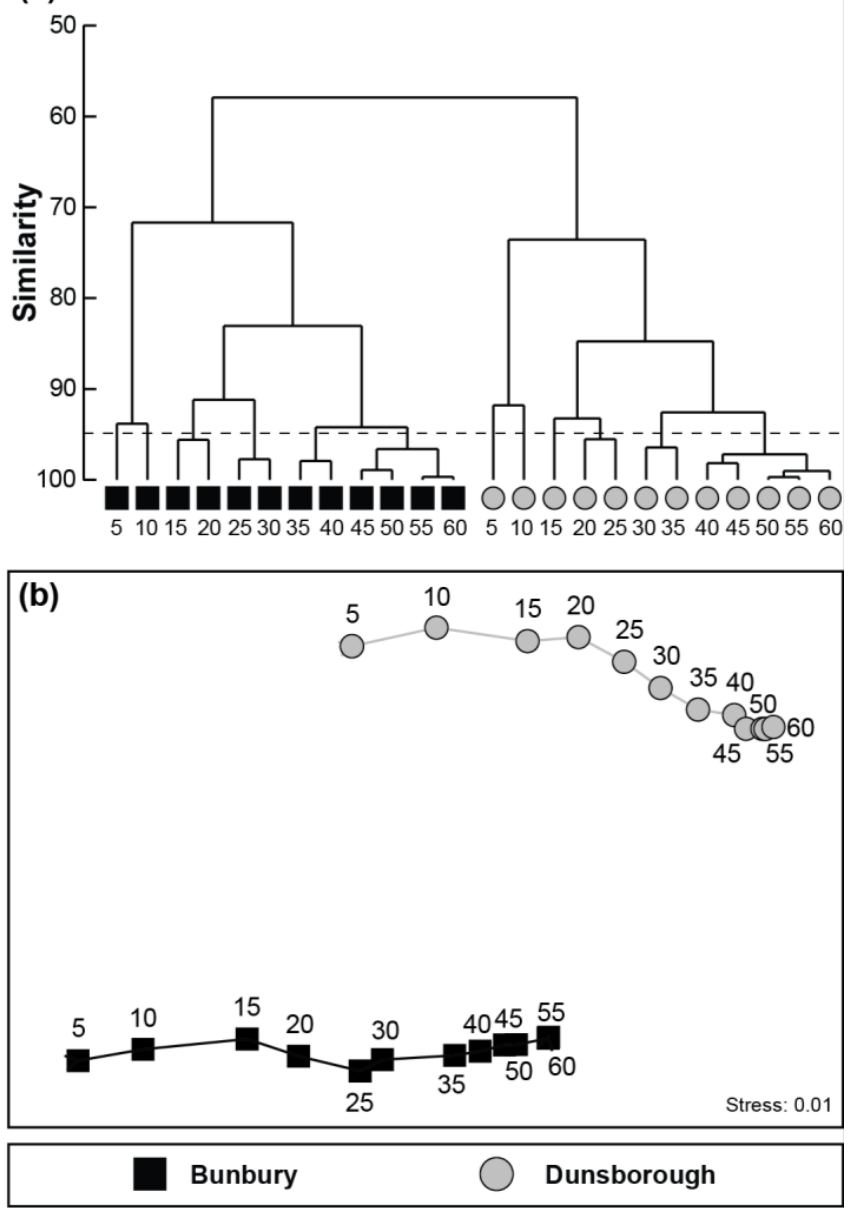

Fig. 4. (a) Cluster dendrogram and (b) nMDS ordination plot, derived from a Bray-Curtis resemblance matrix, constructed from the dispersion-weighted and square-root transformed and averaged MaxN abundances of each species recorded from consecutive five minute intervals of BRUV footage recorded from the Bunbury and Dunsborough artificial reefs between October 2015 and September 2016. Horizontal dashed line denotes a Bray-Curtis similarity of $95 \%$. 


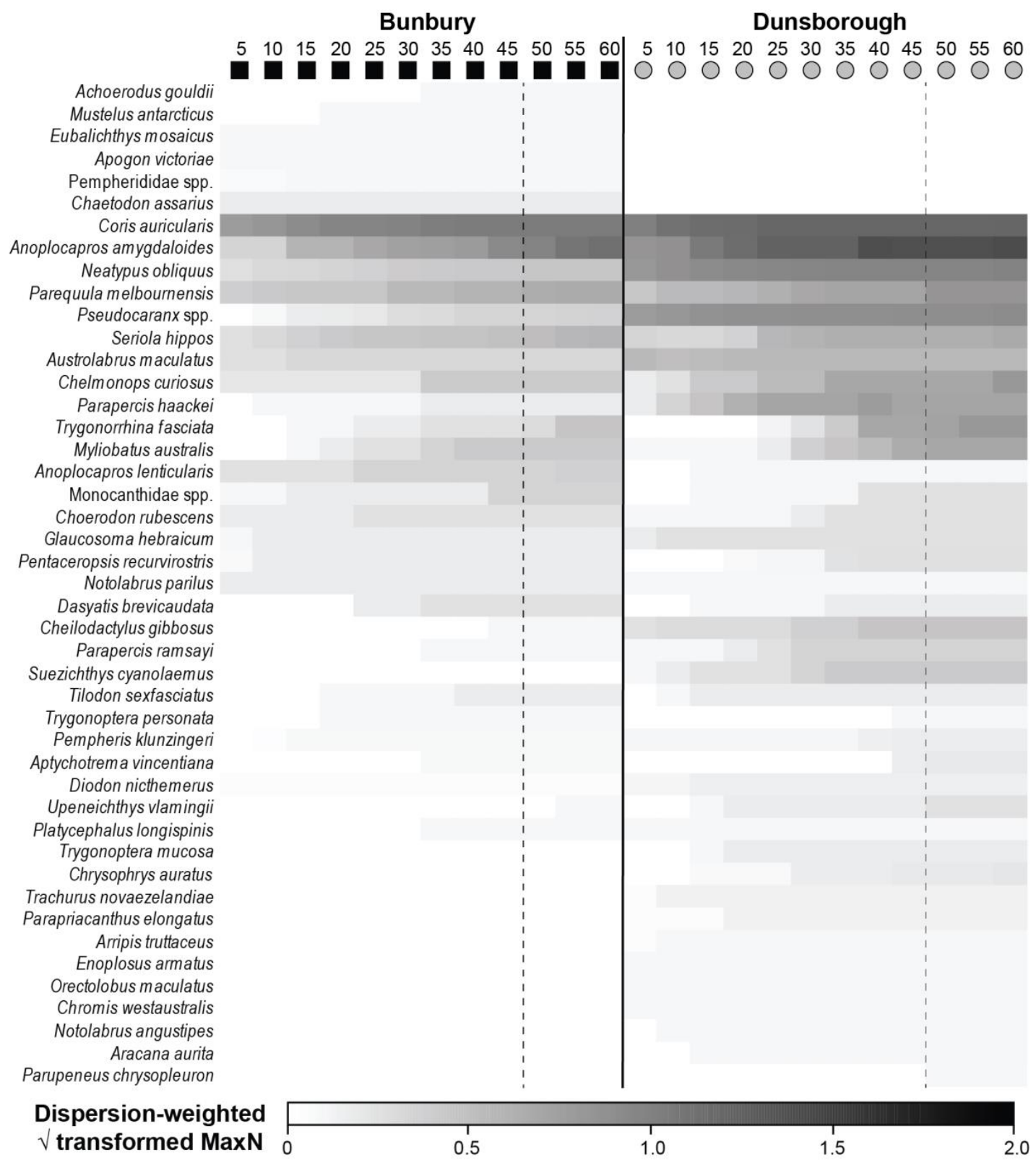

Fig. 5. Shade plot, constructed from the dispersion-weighted, square-root transformed and averaged MaxN abundances of each species recorded from consecutive five minute intervals of BRUV footage recorded from the Bunbury and Dunsborough artificial reefs between October 2015 and September 2016. Vertical dashed line denotes 45 minutes. 
(a)

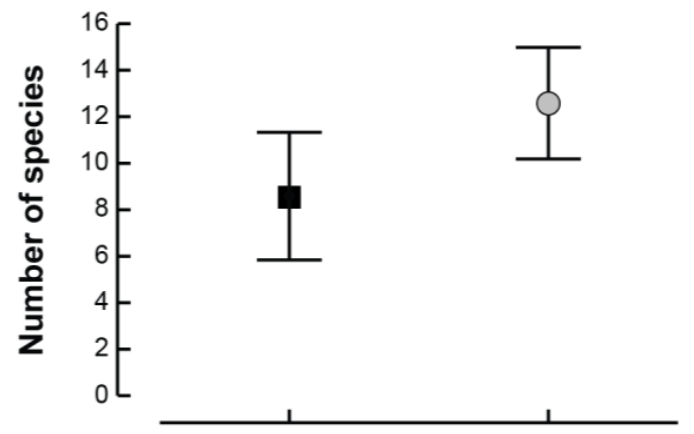

(c)

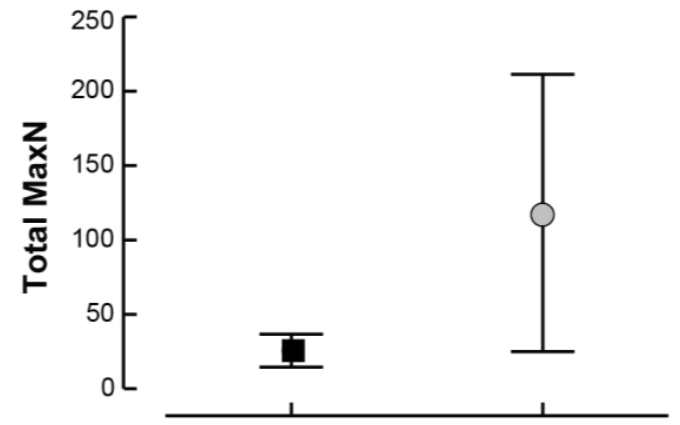

(e)

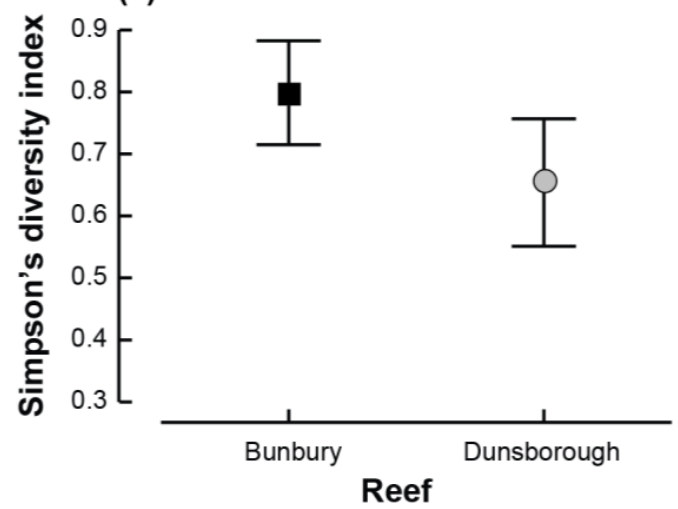

(b)

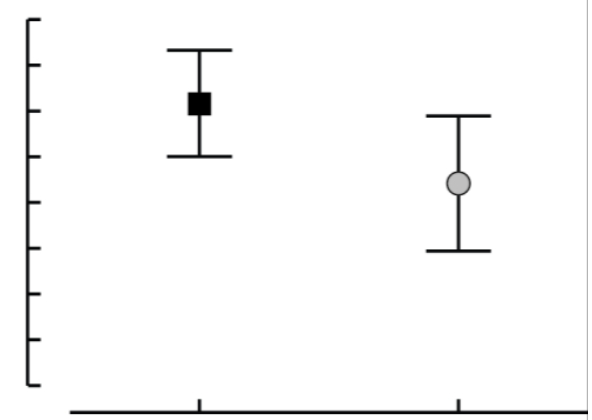

(d)

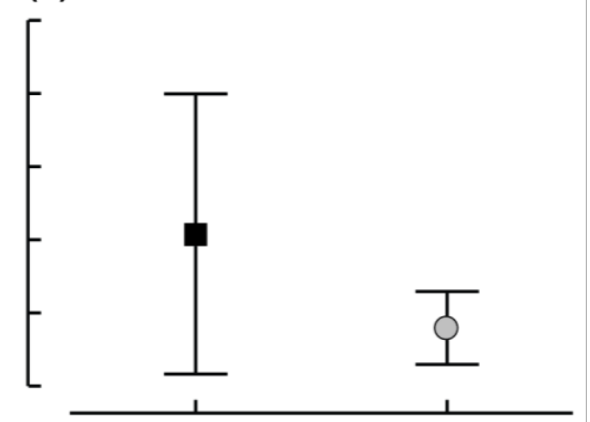

(f)

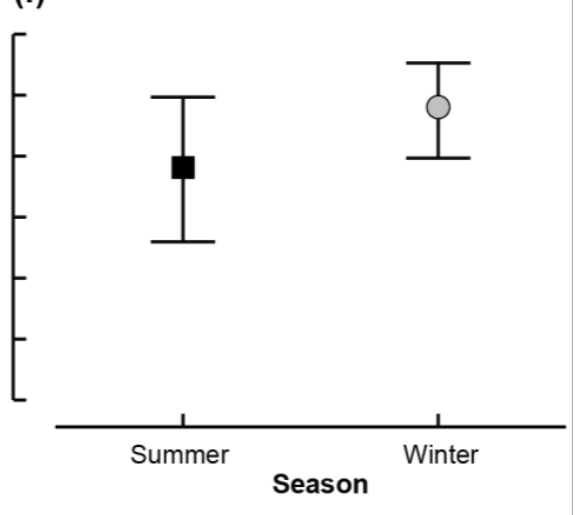

Fig. 6. (a, b) Mean number of species, (c, d) total MaxN and (e, f) Simpson's diversity index recorded between reefs and seasons. Error bars represent $\pm 95 \%$ confidence intervals. 

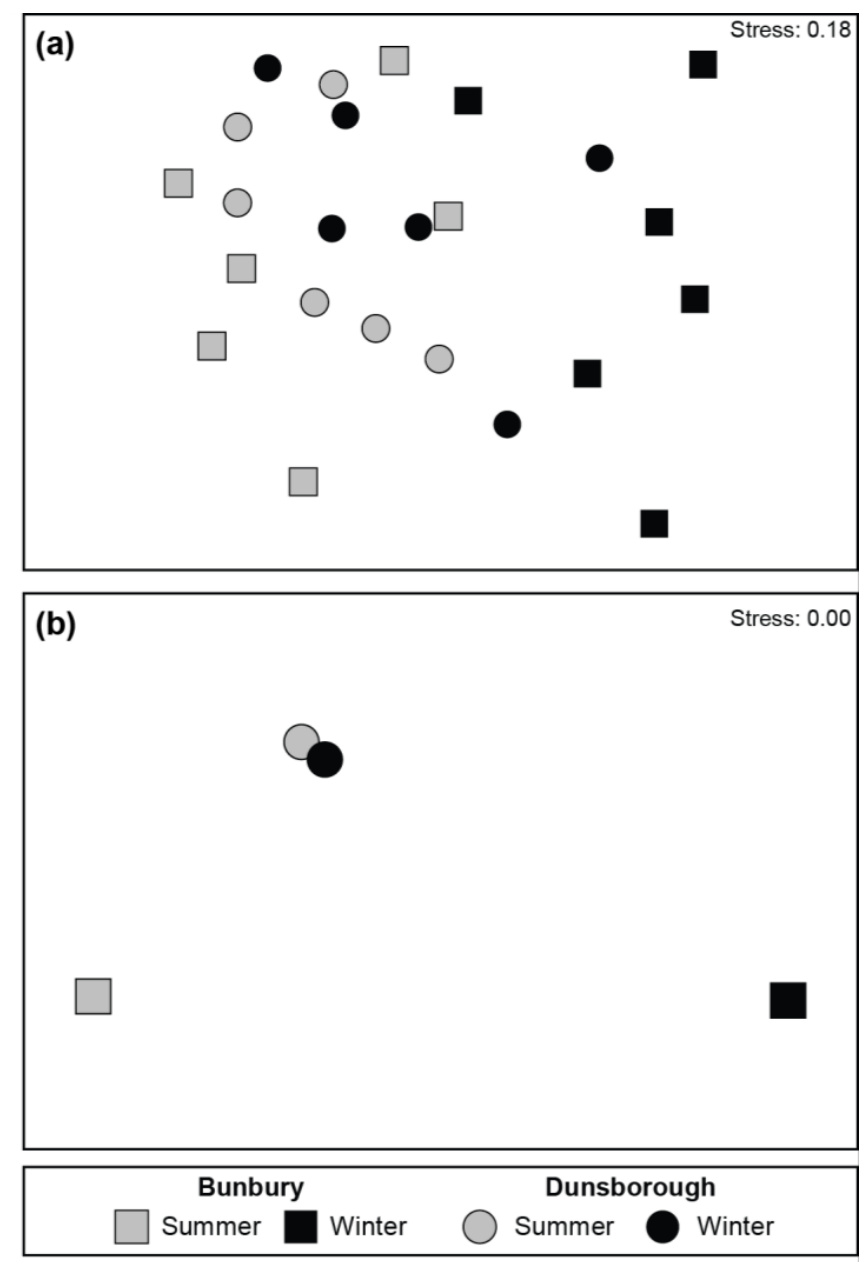

Fig. 7. (a) nMDS ordination plot, derived from a Bray-Curtis resemblance matrix, constructed from the dispersion-weighted and square-root transformed and averaged MaxN abundances of each species recorded from the Bunbury and Dunsborough artificial reefs between October 2015 and September 2016. (b) Centroid nMDS ordination plot, derived from a distance among centroids matrix, constructed from the above Bray-Curtis resemblance matrix. 
(a)

Season

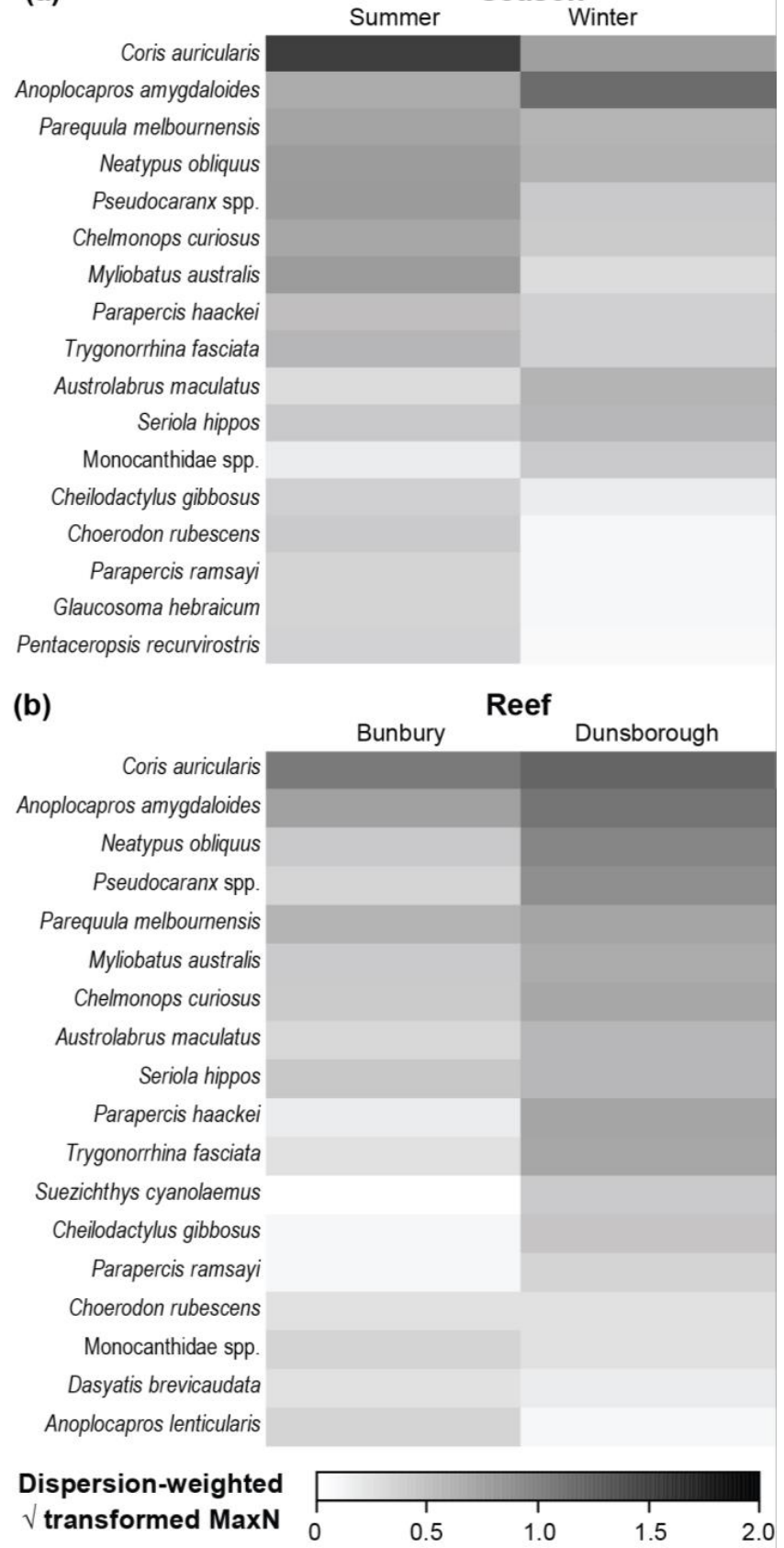

Fig. 8. Shade plots constructed from the dispersion-weighted and square-root transformed MaxN abundances of each species recorded from the Bunbury and Dunsborough artificial reefs between October 2015 and September 2016. MaxN abundances averaged for the (a) two seasons and (b) artificial reefs. Note only species that contributed $\geq 2.5 \%$ to the total number of fish to either reef or season are included. 